\title{
DESENVOLVIMENTO DO MERCOSUL: UMA AVALIAÇÃO DOS FLUXOS DE COMÉRCIO
}

\section{MERCOSUR DEVELOPMENT: AN ASSESSMENT OF TRADE FLOWS}

\author{
Rubiane Daniele Cardoso \\ Universidade Católica de Brasília - Brasília - DF - Brasil \\ Mirian Beatriz Schneider \\ Universidade Estadual do Oeste do Paraná - Toledo - PR - Brasil \\ André Ricardo Bechlin \\ Universidade Estadual do Paraná - Paranavaí - PR - Brasil
}

\begin{abstract}
Resumo: Este artigo procura analisar os efeitos da constituição do Mercado Comum do Sul MERCOSUL nos fluxos de comércio dos países-membros no período de 1994 a 2009, utilizando um modelo gravitacional estendido, que inclui variáveis dummy para o MERCOSUL, para União Européia - UE e North American Free Trade Agreement - NAFTA (por serem blocos econômicos importantes), para os setores da economia e para cada país-membro. Os resultados mostram que $o$ MERCOSUL obteve os maiores aumentos de comércio entre todos os esquemas de integração regionais relevantes para os países-membros, o que ressalta sua importância. Quando considerada a análise dos setores, apenas agricultura teve valor expressivo, mostrando que os produtos deste setor foram predominantes na pauta de exportação dos países do MERCOSUL para todos os países da amostra, tanto em 1994 quanto em 2009.
\end{abstract}

Palavras-chave: MERCOSUL. Exportações. Desenvolvimento Regional. Equação gravitacional.

Abstract: This paper search to analyze the effects of the formation of Mercosur Preferential Trade Agreement trade flows of member countries in the 1994-2009 period, using an extended gravity model that includes dummy variables for Mercosur, for UE and NAFTA (importants economic blocs), for the sectors of the economy and member country. The results show that Mercosur obtained the largest increases in trade among all regional integration schemes relevant to member countries, which highlights its importance for the members. When considering the analysis of the sectors, only agriculture had significant value, showing that the products were still predominant in this sector in the export of the Mercosur countries to all countries in the sample both in 1994, as in 2009.

Keywords: Mercosur. Exports. Regional Development. Gravity Equation.

\section{INTRODUÇÃO}

O MERCOSUL, considerado, na realidade, uma união aduaneira imperfeita, é formado por Brasil, Argentina, Paraguai e Uruguai. Sua constituição legal se deu em 26 de março de 1991, pelo Tratado de Assunção, quando Brasil e Argentina convidaram o Uruguai e o Paraguai para participar do processo integracionista em curso (MELO, 1999). A questão do comércio internacional, no contexto do bloco, sempre despertou interesse, pois os países constituintes apresentam estruturas econômicas muito distintas e, portanto, posições muito diferenciadas em relação ao comércio. 
O objetivo desta pesquisa é analisar os efeitos do fluxo de comércio do MERCOSUL nos países-membros. A análise verifica se o processo integracionista, pela ótica do comércio bilateral e suas complementaridades, foi realmente positivo para todos os países integrantes do bloco, bem como a sua evolução no período analisado. Quanto à definição temporal, utiliza-se dados seccionais para os anos de 1994, 1998, 2002, 2006 e 2009. A escolha do período foi motivada por contemplar uma fase em que constituíam o bloco apenas os países que o originaram, e ainda por abordar momentos importantes vividos por esses países, como crises, ascensões e mudanças políticas.

Os efeitos dos fluxos comerciais do MERCOSUL sobre os países-membros podem ser capturados pelo aumento do comércio dos países (Brasil, Argentina, Paraguai e Uruguai) com o MERCOSUL. Nesse sentido, o modelo gravitacional é muito utilizado por sua capacidade de isolar os efeitos da formação do bloco dos demais fatores que influenciam seu padrão de comércio, permitindo uma inferência direta do seu impacto sobre o comércio dos países integrantes.

Nas pesquisas realizadas nos últimos anos utilizando o modelo, as equações estimadas incluem, além das variáveis básicas (distância, renda), outras que representam características importantes no comércio internacional, como idioma e fronteiras geográficas comuns. Como o objetivo da pesquisa é estudar a relação intrarregional do MERCOSUL do ponto de vista dos principais setores da economia, além das variáveis básicas, foram adicionadas variáveis dummies ${ }^{1}$ que capturam o efeito da criação de comércio em relação ao bloco. Foram criadas dummies para o MERCOSUL, o NAFTA, a UE e uma dummy para cada um dos três setores abordados na pesquisa (agrícola, recursos naturais e produtos manufaturados), e ainda uma dummy para cada país-membro do MERCOSUL.

\section{REFERENCIAL QUANTITATIVO: O MODELO GRAVITACIONAL}

O modelo de análise proposto é o modelo gravitacional, que possui esse nome por fazer uma analogia à Lei da Gravitação Universal. No modelo gravitacional, o comércio seria diretamente proporcional à renda dos países e inversamente proporcional à distância. Ele foi criado na década de 1960, por Tinbergen (1962) e Pöyhönen (1963) e, anos depois, foi aperfeiçoado por Linnemann (1966). Esses autores forneceram as variáveis básicas e suas proxies para determinar o comércio bilateral entre países.

O objetivo inicial de Tinbergen (1962) era analisar os fatores que explicam a amplitude dos fluxos comerciais entre dois países. Os fatores eram classificados em três tipos: o primeiro, abrangia os relacionados à oferta potencial total do país exportador; o segundo, incluía aqueles relacionados à demanda potencial total do país importador. Por fim, o terceiro conjunto de fatores foi a resistência ao comércio entre os países, seja ela natural ou artificial. A resistência natural ao comércio foi definida como sendo os obstáculos impostos pela natureza, como custos de transporte, tempo de transporte, etc. Já a resistência artificial seria

\footnotetext{
${ }^{1}$ As variáveis dummy ou binárias são formas de agregar informações qualitativas em modelos de regressão estatística. Elas podem assumir os valores 0 ou 1, por exemplo: assumem valor 1 quando o país fizer parte do grupo a que se refere a dummye 0 caso contrário.
} 
aquela imposta pelos governos com medidas como tarifas de importação, restrições quantitativas, barreiras sanitárias, etc.

De acordo com Azevedo (2004), a expectativa é que o comércio entre dois países aumente com o tamanho de sua economia, servindo o Produto Interno Bruto - PIB e o PIB per capita como variáveis independentes. O esperado é que coeficientes associados ao PIB dos países exportadores e importadores apresentem um sinal positivo, pois, na maioria dos casos, quanto maior é o país, maior é a variedade de excedente exportável e maior é o gosto pela variedade no consumo.

A distância entre dois países também seria uma variável independente, ilustrando a resistência ao comércio. O sinal esperado para esse coeficiente é negativo, já que, com o aumento na distância, o comércio tende a diminuir (SÁ PORTO, 2002). Variáveis dummy também já foram incluídas no modelo, especialmente aquelas representando acordos preferenciais de comércio, a fim de estudar tais acordos. A forma original (da década de 1960) da equação gravitacional aplicada ao comércio internacional tinha a seguinte forma:

$$
X_{i j}=a_{0}\left(Y_{i}\right)^{a_{1}}\left(Y_{j}\right)^{a_{2}}\left(N_{i}\right)^{a_{3}}\left(N_{j}\right)^{a_{4}}\left(\text { Dist }_{i j}\right)^{a_{5}} e^{(\operatorname{Pr} e f)^{a_{6}}}\left(e_{i j}\right)
$$

Em que:

$X_{i j}$ é o valor nominal das exportações do país i para o país j; $Y_{i}$ é o valor nominal do PIB do país $i_{i} Y_{j}$ é o valor nominal do PIB do país j; $N_{i}$ é a população do país $i_{i} N_{j}$ é a população do país j; Dist ij é a distância entre os centros comerciais dos dois países, utilizada para representar as variáveis de resistência ao comércio; Pref é uma variável dummy cujo valor é 1, caso os dois países pertençam a uma área específica de comércio preferencial, e 0 nos demais casos; e $e_{i j}$ é o termo de erro. Os coeficientes de $a_{0}$ a $a_{6}$ devem ser calculados por regressão econométrica.

Referente a essa formulação original, a principal limitação do modelo gravitacional era a falta de uma fundamentação microeconômica teórica sólida. $O$ modelo descrito pela Equação 1 não é um modelo econômico, embora seja um modelo plausível (SÁ PORTO, 2002). Não existia a menção de quaisquer fatores ou níveis tecnológicos relativos e, portanto, faltava essa ligação com a teoria neoclássica do comércio internacional (HARRIGAN, 2001).

Alguns autores contribuíram para melhor fundamentação teórica ao modelo gravitacional, como, por exemplo, Anderson (1979), Bergstrand (1985 e 1989), Deardorff (1998) e Anderson e Van Wincoop (2003). Além disso, outros autores complementaram o modelo gravitacional adicionando variáveis explicativas ao modelo-padrão reduzido, como distância absoluta e relativa, deflator do PIB, taxa de câmbio, índice de abertura de um país, entre outros, visando aumentar o poder explanatório do modelo (SÁ PORTO, 2002).

Anderson (1979) buscou trazer uma base microeconômica mais concreta para o modelo, propondo explicar a equação gravitacional tendo por base um sistema Cobb-Douglas de gastos. O autor presume a existência de preferências homotéticas idênticas em todas as regiões e a diferenciação de produtos segundo o país de origem (contudo, Anderson não conseguiu identificar a parte da equação que era necessária).

Bergstrand (1985) estendeu as bases teóricas da equação gravitacional, adicionando variáveis que representassem preço - o modelo seria obtido por um comportamento maximizador por parte dos agentes de $N$ países, com a pressuposição de um fator único de produção de cada país. Já em 1989, o autor 
incorporou ao modelo fatores e variáveis não homotéticas - o modelo agora seria com dois setores com produtos diferenciados, dois fatores (capital e mão de obra) e $N$ países.

Posteriormente, Anderson e Van Wincoop (2001) defenderam que o comércio entre dois países (ou regiões) não diminui apenas devido à distância, mas também devido às barreiras bilaterais de comércio (resistência multilateral). Tal variável captaria o efeito das barreiras com outros parceiros e quanto mais um país for resistente no que se refere ao comércio com o resto do mundo, mais se presume que ele será induzido a comerciar com um determinado parceiro bilateralmente.

No trabalho intitulado Gravity with Gravitas: a solution to the border puzzle, Anderson e Van Wincoop (2001) desenvolveram um modelo gravitacional modificado para tentar solucionar a questão das fronteiras. Os autores defendem que, isolando o efeito das variáveis tamanho, o comércio bilateral vai depender do valor da barreira existente (distância e barreiras tarifárias impostas) entre dois determinados países, dividida pelo valor da resistência multilateral.

De acordo com Sá Porto (2002), o modelo gravitacional possui outra limitação quanto à fundamentação microeconômica - a questão da produção não é levada em conta no modelo tradicional. Só após o surgimento da "nova teoria do comércio" na década de 1980 é que foi possível abordar a questão da produção ${ }^{2}$.

Existem também alguns problemas do ponto de vista econométrico do modelo. Seja em seu formato padrão ou na forma aumentada, o modelo tem sido calculado utilizando-se dados seccionais. Por exemplo, escolhe-se um período de tempo (vários anos) ou apenas um ponto no tempo e avalia-se como evoluíram os coeficientes estimados.

Ocorre, porém, que, mesmo tendo um alto valor para $\mathrm{R}^{2}$, o problema se encontra no fato de que o modelo pode subestimar o volume de comércio dos países que comercializam bastante, e superestimar o volume de comércio dos países que comercializam pouco, o que resulta na presença de heterogeneidade. Tal problema é contornado por Cheng e Wall (1999) ao removerem o pressuposto de que o intercepto da equação deve ser o mesmo para todos os pares de países ${ }^{3}$. $\mathrm{Na}$ próxima seção estão demostrados os passos básicos para a estimação da equação gravitacional aqui utilizada.

\subsection{Estimação do modelo}

O modelo gravitacional tem sido bastante utilizado para examinar acordos preferenciais de comércio - APC, principalmente por sua capacidade de explicar o comércio bilateral. Por intermédio de variáveis dummies, o modelo permite identificar o impacto dos blocos econômicos no comércio intra e extrabloco. Vale destacar a capacidade que o modelo tem de separar os efeitos dos APCs das demais variáveis que explicam o padrão de comércio internacional. A equação gravitacional explica o comércio "normal" entre um par de países na ausência de

\footnotetext{
2 Pode-se citar, como exemplo, o modelo de competição monopolística. Sobre isso, ver Helpman e Krugman (1985).

3 Sobre isso, ver também Sá Porto e Canuto (2004).
} 
um APC, enquanto a dummy relacionada ao bloco captura o comércio adicional atribuído especificamente ao bloco (AZEVEDO, 2004).

Um desenvolvimento relevante na especificação dos modelos gravitacionais se refere à forma pela qual o impacto do APC é medido pela variável dummy em um âmbito intrarregional. Os primeiros experimentos empregaram somente uma variável dummy para captar os efeitos dos APCs exclusivamente sobre o comércio intrabloco. ${ }^{4}$ Se o coeficiente associado à dummy intrabloco é positivo e significativo, é sinal que esses países têm um comércio maior entre si do que poderia ser previsto pelas demais variáveis do modelo, sugerindo que o APC leva a uma criação bruta de comércio - que, segundo Balassa (1967), refere-se a uma elevação do comércio intrabloco causado pela integração sem considerar se ele substitui a produção doméstica (criação externa de comércio) ou as exportações de países de fora do bloco (desvio de comércio).

Para se avaliar o efeito do MERCOSUL sobre os países-membros, especificamente sobre seus setores principais - indústria, recursos naturais e agricultura, será utilizado um modelo gravitacional em seu formato tradicional ao invés de um modelo gravitacional do tipo de Bröcker ${ }^{5}$ (1988) ou um dos modelos de equilíbrio geral computável. Tais modelos, embora possam resultar em uma estimativa mais precisa, utilizam uma gama muito maior de dados, e muitos deles de difícil acesso, além de serem ainda mais complicados de se estimar.

Nesse contexto, primeiramente foram adicionadas ao modelo-padrão duas variáveis dummy: uma dummy para o MERCOSUL e outra para o setor - industrial ou agrícola. Em um primeiro momento, o modelo gravitacional será utilizado de forma agregada somente com a variável Mercosul para os anos de 1990, 1994, 1998, 2002, 2004 e 2008, estimando como a medida "aumento de comércio" dos países-membros com o MERCOSUL evoluiu ao longo do período de 1990 a 2008. O ano de 1990 foi utilizado para um efeito comparativo, já que foi um período anterior à formação do bloco. Quanto aos outros pontos no tempo que serão analisados, eles correspondem a períodos interessantes, períodos em que ocorreram mudanças e crises cambiais que afetaram acentuadamente o bloco, bem como o comércio internacional como um todo.

Os coeficientes serão estimados utilizando-se o Método dos Mínimos Quadrados Ordinários - MQO, ${ }^{6}$ seguindo uma especificação log-linear, o que permite interpretar os coeficientes como elasticidades. Conforme salientam Cuairan, Sanso e Sanz (1993), embora não seja ótima, a especificação log-linear representa uma aproximação satisfatória da forma funcional ótima. A primeira forma do modelo a ser estimado é o que segue:

$$
\ln X_{i j t}=\ln a_{0}+a_{1} \ln Y_{i t}+a_{2} \ln Y_{j t}+a_{3} \ln Y N_{i t}+a_{4} \ln Y N_{j t}+a_{5} \ln D i s t_{i j t}+\ln e_{i j}
$$

Em que:

$X_{i j}$ é o valor corrente (US\$) das exportações do país $i$ ao país j; $Y_{i}$ é o valor nominal (US\$) do PIB do país i no período $t, Y_{j}$ é o valor nominal (US\$) do PIB do país $j$ no período $t, N_{i}$ é a população do país $i$ no período $t, N_{j}$ é a população do país $j$ no

\footnotetext{
${ }^{4}$ Sobre o assunto, ver Aitken (1973) e Frankel, Stein e Wei (1995).

${ }^{5}$ Bröcker (1988) utilizou um modelo incluindo dados de oferta e demanda regionais, fluxos comerciais internacionais e inter-regionais e distância entre as regiões de quatro países do Norte Europeu.

${ }^{6}$ Ver Cheng e Wall (1999).
} 
período $t_{1}$ Dist $i_{i j}$ é a distância entre os centros comerciais dos dois países; $e_{i j}$ é o termo de erro.

Na Equação 2, $X_{i j}$ é o fluxo de comércio (exportações) entre um dos paísesmembros do MERCOSUL e os países dos principais blocos econômicos mundiais, além dos países de referência. Os países utilizados nesta pesquisa foram: Brasil, Argentina, Paraguai, Uruguai (MERCOSUL); Canadá, México, EUA (NAFTA); Alemanha, Áustria, Bélgica, Bulgária, Chipre, Dinamarca, Eslováquia, Eslovênia, Espanha, Estônia, Finlândia, França, Grécia, Hungria, Irlanda, Itália, Letônia, Lituânia, Luxemburgo, Malta, Países Baixos, Polônia, Portugal, Reino Unido, República Tcheca, Romênia, Suécia (UE); China, Japão, Coreia do Sul, Chile, Venezuela, Colômbia, Índia, Arábia Saudita e Nigéria (países de referência). O MERCOSUL também está incluso entre os principais blocos econômicos, podendose explorar o comércio intrarregional, que é o foco deste estudo.

Os dados utilizados foram coletados nas seguintes fontes: os dados de comércio internacional (exportação) foram coletados na United Nations Commodity Trade Statistics Database (UN Comtrade, 2010). Os dados de PIB e população foram coletados no The World Bank (2010). Por fim, os dados de distância foram obtidos no World Atlas (2010).

Em um segundo momento, foi adicionada à Equação 2 a variável dummy referente ao MERCOSUL (Equação 3). Isso é interessante porque seu coeficiente demonstra o aumento no fluxo de comércio que os países-membros, como um todo, obtêm com o comércio intrabloco, ou seja, qual foi o efeito da constituição do bloco sobre seus padrões de comércio (dadas as preferências comerciais).

$\ln X_{i j t}=\ln a_{0}+a_{1} \ln Y_{i t}+a_{2} \ln Y_{j t}+a_{3} \ln Y N_{i t}+a_{4} \ln Y N_{j t}+a_{5} \ln$ Dist $_{i j t}+$ $a_{6} \operatorname{Merc}+\ln e_{i j}$

Posteriormente, foram adicionadas ao modelo variáveis dummies referentes aos principais blocos econômicos (NAFTA, UE), que, complementando a análise, demonstram o aumento do fluxo de comércio dos países-membros do MERCOSUL com esses blocos (Equação 4).

$\ln X_{i j t}=\ln a_{0}+a_{1} \ln Y_{i t}+a_{2} \ln Y_{j t}+a_{3} \ln Y N_{i t}+a_{4} \ln Y N_{j t}+a_{5} \ln$ Dist $_{i j t}+$ $a_{6}$ Merc $+a_{7}$ Nafta $+a_{8} U e+\ln e_{i j}$

Em seguida, foi adicionada uma dummy para setor, que aborda cada um dos três setores da economia (setor agrícola, recursos naturais e manufaturados) ${ }^{7}$. Essa variável demonstra se as exportações das principais commodities se originaram do setor agrícola, de recursos naturais ou do setor industrial, o que possibilita perceber a importância desses setores para o MERCOSUL ao longo do período analisado, bem como a sua evolução. O modelo estimado foi o seguinte ${ }^{8}$ : $\ln X_{i j t}=\ln a_{0}+a_{1} \ln Y_{i t}+a_{2} \ln Y_{j t}+a_{3} \ln Y N_{i t}+a_{4} \ln Y N_{j t}+a_{5} \ln D_{i s t_{i j t}}+$ $a_{6}$ Merc $+a_{7}$ Nafta $+a_{8} U e+a_{9}$ Set $+\ln e_{i j}$

Na Equação 5, $X_{i j k}$ é o valor das exportações do setor k do país i ao país j; todas as outras variáveis são definidas tal como na Equação 2. A variável dummy Set será igual a 1 se o fluxo de comércio for referente ao setor abordado, e 0 se o fluxo de comércio não for referente a esse setor.

\footnotetext{
${ }^{7}$ Essa classificação de produtos mapeia os 21 grupos de produtos da NBM-SH (Norma Brasileira de Mercadorias - Sistema Harmonizado) e os sintetiza em três grupos escolhidos pela autora.

${ }^{8}$ Essa equação foi rodada três vezes, uma vez com cada dummy - Agric (setor agrícola), Natres (setor recursos naturais) e Man (setor manufaturados), para analisar o efeito individual.
} 
Foi realizada a análise do efeito do fluxo de comércio do MERCOSUL sobre cada país-membro, que se deu por meio da inclusão de uma variável dummy País, que aborda cada um dos quatro países (Bra., Par., Uru. e Arg.). Essa variável assume o valor 1 quando as exportações dos países-membros do MERCOSUL (país i) se destinam ao referido país (Brasil, Argentina, Paraguai ou Uruguai) e 0 se forem destinadas aos demais países da amostra. A equação estimada é apresentada a seguir:

$\ln X_{i j t}=\ln a_{0}+a_{1} \ln Y_{i t}+a_{2} \ln Y_{j t}+a_{3} \ln Y N_{i t}+a_{4} \ln Y N_{j t}+a_{5} \ln$ Dist $_{i j t}+$ $a_{6}$ Merc $+a_{7}$ Nafta $+a_{8} U e+a_{9}$ País $+\ln e_{i j}$

$\mathrm{Na}$ Equação 6, País assume Bra., Par., Uru. e Arg., e todas as outras variáveis são definidas tal qual a Equação 5, anterior, com exceção da variável dummy Set, que não foi incluída nesse momento. Novamente, esse é um caso em que a equação que foi rodada quatro vezes, uma vez com cada dummy - Bra (Brasil), Arg (Argentina), Par (Paraguai) e Uru (Uruguai), para analisar o efeito individual.

Sabe-se que o modelo gravitacional pode ser estimado de vários modos, existindo a possibilidade de se incluírem outras variáveis dummy que podem melhor ou pior corroborar determinado objetivo. Então, ao se rodarem os dados, foram necessários ajustes quanto a correções próprias de modelos econométricos, bem como na própria concepção da equação.

Destaca-se que a análise foi realizada no Software Eviews 5 e os resultados serão pormenorizados a seguir.

\section{DESENVOLVIMENTO DO MERCOSUL: UMA ANÁLISE DOS FLUXOS COMERCIAIS}

Com um PIB que corresponde a mais de dois terços do PIB total do MERCOSUL, ou seja, cerca de $80 \%$ do total em 2009, o Brasil, desde a oficialização do bloco, sempre se manteve como o país de maior contribuição dentro do MERCOSUL. A participação argentina no PIB do MERCOSUL corresponde praticamente ao restante, cerca de $16 \%$, uma vez que o PIB do Paraguai e o do Uruguai são bastante pequenos em relação ao PIB argentino. Em média, o Paraguai tem correspondido a menos de $1 \%$ do PIB do MERCOSUL, e o Uruguai a algo entre 1 e $2 \%$.

Pode-se perceber, na observação dos dados da Tabela 1, que os fluxos comerciais entre Brasil e Argentina encolheram de forma acentuada até 2002, devido à sequência de crises que afetaram os dois países, inclusive com mudanças de regime cambial no início de 1999, no Brasil, e em fins de 2001 na Argentina. As exportações brasileiras para a Argentina tiveram uma queda de $42 \%$, passando de US\$ 4,0 bilhões em 1995 para 2,3 bilhões em 2002, ao passo que as importações provindas da Argentina diminuíram cerca de $11 \%$, passando de US\$ 5,4 bilhões para US\$ 4,8 bilhões.

Passada a fase de ajustamento, o comércio bilateral entre Brasil e Argentina voltou a crescer rapidamente a partir de 2003. As exportações brasileiras cresceram cerca de 650\% entre 2002 e 2008, enquanto as importações provenientes da Argentina apresentaram uma variação menor, de 173\%. Em 2008, as exportações brasileiras alcançaram US\$17,3 bilhões e as importações, US\$13,2 bilhões. A taxa de crescimento das exportações bem superior à variação 
das importações resultou num superávit comercial crescente e favorável para o Brasil, alcançando no ano de 2008 um patamar de US\$ 4,3 bilhões.

Em 2008, a Argentina foi o $2^{\circ}$ principal destino das exportações brasileiras, sendo responsável por $8,5 \%$ das exportações totais. Em relação às importações, a Argentina foi o $3^{\circ}$ fornecedor, respondendo por $7,6 \%$ das compras brasileiras (MDIC, 2008).

Quanto ao comércio bilateral entre Brasil e Uruguai, este apresentou expressivas oscilações ao longo dos últimos 10 anos. As exportações para o país passaram por períodos de queda entre 1995 e 2002 (um declínio de cerca de 57\%), e iniciaram um processo de recuperação em 2004. Entre 2002 e 2008, as exportações cresceram 345\%, o que representou uma taxa anual média de $57 \%$.

No tocante ao comércio entre Brasil e Paraguai, este apresentou considerável crescimento de 1995 a 2008. Em 1995, o Brasil exportava para o Paraguai US\$ 811 milhões, em 2008 passou para mais de US\$ 1,6 bilhão. Já o Paraguai manteve certa estabilidade nas suas exportações para o Brasil. Algo relevante é o fato de os principais destinos das exportações do Paraguai serem o Uruguai e o Brasil, respectivamente, o que mostra que o Bloco é de grande importância para o setor externo do país.

Tabela 1 - Transações comerciais intrabloco nos anos de 1995/2002/2008/2010 (em milhões US\$ FOB)

\begin{tabular}{|c|c|c|c|c|c|c|}
\hline \multicolumn{7}{|c|}{ País Exportador } \\
\hline \multicolumn{2}{|c|}{ País Importador } & Argentina & Brasil & Paraguai & Uruguai & Total \\
\hline \multirow{4}{*}{ 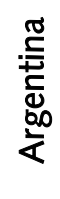 } & 1995 & $x$ & $4.041,10$ & 83,3 & 267,1 & $4.391,50$ \\
\hline & 2002 & $x$ & $2.341,80$ & 34,7 & 113,3 & $2.489,80$ \\
\hline & 2008 & $x$ & $17.605,60$ & 711,9 & 507 & $18.824,50$ \\
\hline & 2010 & $x$ & 18596,2 & 538,1 & 573,5 & $19.707,80$ \\
\hline \multirow{4}{*}{$\begin{array}{l}\overline{\bar{y}} \\
\overline{0} \\
\overline{0}\end{array}$} & 1995 & $5.484,10$ & x & 410,8 & 700,1 & $6.595,00$ \\
\hline & 2002 & $4.848,00$ & $x$ & 353 & 431,8 & $5.632,80$ \\
\hline & 2008 & $13.258,70$ & $x$ & 614,4 & 986,6 & $14.859,70$ \\
\hline & 2010 & 14420,3 & x & 660,5 & 1421,8 & $16.502,60$ \\
\hline \multirow{4}{*}{ 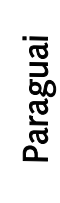 } & 1995 & 631,4 & $1.300,70$ & $x$ & 24,9 & $1.957,00$ \\
\hline & 2002 & 344,7 & 558,4 & $x$ & 61,7 & 964,8 \\
\hline & 2008 & $1.085,60$ & $2.487,50$ & $x$ & 106,9 & $3.680,00$ \\
\hline & 2010 & 1154,2 & 2553,7 & $x$ & 159,8 & $3.867,70$ \\
\hline \multirow{6}{*}{ 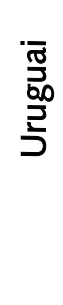 } & 1995 & 662,9 & 811 & 34 & $x$ & $1.507,90$ \\
\hline & 2002 & 530,5 & 410,5 & 165,1 & $x$ & $1.106,10$ \\
\hline & 2008 & $1.762,20$ & $1.644,10$ & 777,4 & $x$ & $4.183,70$ \\
\hline & 2010 & 1552,1 & 1540,5 & 995,7 & $x$ & $4.088,30$ \\
\hline & 1995 & $6.778,40$ & $6.152,80$ & 528,1 & 992,1 & $14.451,40$ \\
\hline & 2002 & $5.723,20$ & $3.310,70$ & 552,8 & 606,8 & $10.193,50$ \\
\hline \multirow{2}{*}{ 胥 } & 2008 & $16.106,50$ & $21.737,20$ & 2103,7 & 1600,5 & $41.547,90$ \\
\hline & 2010 & $17.126,60$ & $22.690,40$ & 2194,3 & 2155,1 & $44.166,40$ \\
\hline
\end{tabular}

Fonte: ALADI (2012). 
O fluxo de comércio entre Argentina e Paraguai seguiu o mesmo padrão, embora em menor valor. Em 1995, a Argentina exportava para o Paraguai cerca de US\$ 631 milhões, em 2008, passou para pouco mais de US\$ 1 bilhão. Já o Paraguai apresentou um crescimento surpreendente nas suas exportações para a Argentina, cerca de 754\% entre 1995 e 2008, passando de US\$ 83 milhões para pouco mais de US\$ 711 milhões.

Quanto ao comércio bilateral entre Argentina e Uruguai, este também teve um aumento relevante no período. Em 1995, a Argentina exportava para o Uruguai cerca de US\$ 662 milhões, já em 2008 o volume era de aproximadamente US\$ 1,8 bilhão, um crescimento de 165\%. Quanto às importações da Argentina advindas do Uruguai, estas aumentaram aproximadamente $90 \%$ no período de análise.

Por fim, o fluxo de comércio entre Paraguai e Uruguai foi diferenciado quanto ao padrão que se seguiu o comércio entre os demais membros nos anos de análise (1995-2002: período de declínio, 2002-2008: período de crescimento). Entre 1995 e 2002, o Paraguai aumentou em 385\% suas exportações para o Uruguai, e as importações cresceram cerca de 147\%. Quanto ao período de 2002 a 2008, as exportações paraguaias passaram de US\$165 milhões para US\$777 milhões, um aumento de aproximadamente $371 \%$. Já as importações advindas do Uruguai aumentaram cerca de 73\%, passando de US\$ 61 milhões em 2002 para mais de US\$ 106 milhões em 2008.

A partir de 2002, vem ocorrendo gradual e consistente crescimento do comércio intrabloco. Em 2010, as exportações entre países do MERCOSUL já representaram quase $16 \%$ de suas exportações globais.

\subsection{Análise do modelo gravitacional para o MERCOSUL}

Para melhor alcançar os objetivos propostos nesta pesquisa, foram estimadas algumas formas alternativas para a equação gravitacional original. Mesmo assim, no entanto, em primeiro lugar foi estimado o modelo gravitacional original, sem as variáveis dummy. Essa equação foi incluída para se avaliar qual o efeito sobre os coeficientes das variáveis renda, população e distância, caso as variáveis dummy fossem removidas do modelo (Equação 1 na Tabela 2).

Para analisar o papel do MERCOSUL no desenvolvimento regional de seus países-membros foi utilizado o modelo gravitacional em seu formato tradicional, ao invés de um modelo do tipo de Bröcker (1988), como visto anteriormente. Assim, na Equação 2 (Tabelas 2 e 3) foi adicionada ao modelo a dummy para o MERCOSUL (Merc). Posteriormente, foram adicionadas as variáveis dummy para o NAFTA (Nafta) e para a UE (Ue), para se avaliar o efeito em conjunto (Equação 3 nas Tabelas 3 e 4). Após isso, para verificar a importância de cada setor abordado na pesquisa, foi adicionada a dummy para o setor (Set). Nesse caso, a equação foi estimada 3 vezes, uma vez para cada setor (agrícola, recursos naturais e manufaturados) e os resultados estão expostos nas Tabela 2 e 3, nas equações 4, 5 e 6, respectivamente.

Cabe salientar que se tentou resolver dois problemas econométricos potenciais. O primeiro é a possibilidade de haver uma simultaneidade, já que a variável dependente (exportações) é um componente de uma das variáveis independentes (PIB). Assim sendo, de acordo com McCallum (1995), por uma 
identidade contábil, haverá correlação de uma das variáveis independentes com o erro. Foi estimada, então, a Equação 2 (que inclui a dummy para o MERCOSUL) com as variáveis logaritmo das populações $N_{i t}$ e $N_{j t}$ substituindo as variáveis dos PIBs $Y_{i t}$ e $Y_{j t}$ (Equação 7). ${ }^{9}$ Já o segundo problema é a heterocedasticidade, ou seja, o erro apresenta diferentes variâncias. Para a correção desse problema, foram estimadas novamente as sete equações usando erros-padrão com heterocedasticidade consistente (heteroscedasticity-consistent standard error estimates), seguindo White (1980).

Tabela 2. Estimativas para os coeficientes da equação gravitacional para os fluxos comerciais entre os países-membros do MERCOSUL e seus principais parceiros comerciais - 1994

\begin{tabular}{|c|c|c|c|c|c|c|c|}
\hline \multirow[b]{2}{*}{$\begin{array}{c}\text { Var. } \\
\text { independente }\end{array}$} & \multicolumn{5}{|c|}{ Equação } & \multirow[b]{2}{*}{6} & \multirow[b]{2}{*}{7} \\
\hline & 1 & 2 & 3 & 4 & 5 & & \\
\hline$Y_{i t}$ & $\begin{array}{l}1.14^{*} \\
(0.16)\end{array}$ & $\begin{array}{l}1.10^{*} \\
(0.16)\end{array}$ & $\begin{array}{l}1.11^{*} \\
(0.16)\end{array}$ & $\begin{array}{l}1.06^{*} \\
(0.15)\end{array}$ & $\begin{array}{l}1.10^{*} \\
(0.16)\end{array}$ & $\begin{array}{l}1.05^{*} \\
(0.15)\end{array}$ & - \\
\hline$Y_{j t}$ & $\begin{array}{l}0.95^{*} \\
(0.06)\end{array}$ & $\begin{array}{l}0.97^{*} \\
(0.06)\end{array}$ & $\begin{array}{l}1.02 * \\
(0.06)\end{array}$ & $\begin{array}{l}1.01^{*} \\
(0.06)\end{array}$ & $\begin{array}{l}1.02^{*} \\
(0.06)\end{array}$ & $\begin{array}{l}1.00^{*} \\
(0.06)\end{array}$ & - \\
\hline$N_{i t}$ & $\begin{array}{c}0.07 \\
(0.15)\end{array}$ & $\begin{array}{c}0.10 \\
(0.15)\end{array}$ & $\begin{array}{c}0.10 \\
(0.15)\end{array}$ & $\begin{array}{c}0.14 \\
(0.15)\end{array}$ & $\begin{array}{c}0.10 \\
(0.15)\end{array}$ & $\begin{array}{c}0.14 \\
(0.15)\end{array}$ & $\begin{array}{c}1.12^{*} \\
(0.05)\end{array}$ \\
\hline$N_{j t}$ & $\begin{array}{c}0.10 \\
(0.07)\end{array}$ & $\begin{array}{l}0.05 \\
(0.07)\end{array}$ & $\begin{array}{c}0.01 \\
(0.08)\end{array}$ & $\begin{array}{c}0.02 \\
(0.08)\end{array}$ & $\begin{array}{c}0.01 \\
(0.08)\end{array}$ & $\begin{array}{c}0.02 \\
(0.08)\end{array}$ & $\begin{array}{l}0.81^{*} \\
(0.05)\end{array}$ \\
\hline Dist $_{i j}$ & $\begin{array}{l}-1.80^{*} \\
(0.10)\end{array}$ & $\begin{array}{l}-1.45^{*} \\
(0.12)\end{array}$ & $\begin{array}{l}-1.46^{*} \\
(0.13)\end{array}$ & $\begin{array}{l}-1.47^{*} \\
(0.13)\end{array}$ & $\begin{array}{l}-1.46^{*} \\
(0.13)\end{array}$ & $\begin{array}{l}-1.45^{*} \\
(0.12)\end{array}$ & $\begin{array}{l}-1.08^{*} \\
(0.11)\end{array}$ \\
\hline Mercosul & - & $\begin{array}{l}1.30^{*} \\
(0.23)\end{array}$ & $\begin{array}{l}1.14^{*} \\
(0.23)\end{array}$ & $\begin{array}{l}1.14^{*} \\
(0.24)\end{array}$ & $\begin{array}{l}1.14^{*} \\
(0.23)\end{array}$ & $\begin{array}{l}1.11^{*} \\
(0.23)\end{array}$ & $\begin{array}{l}1.07^{*} \\
(0.27)\end{array}$ \\
\hline Nafta & - & - & $\begin{array}{l}-0.59^{*} \\
(0.27)\end{array}$ & $\begin{array}{l}-0.59^{*} \\
(0.28)\end{array}$ & $\begin{array}{l}-0.59^{*} \\
(0.27)\end{array}$ & $\begin{array}{l}-0.57^{*} \\
(0.27)\end{array}$ & - \\
\hline Ue & - & - & $\begin{array}{l}-0.23 \\
(0.19)\end{array}$ & $\begin{array}{l}-0.29 \\
(0.19)\end{array}$ & $\begin{array}{l}-0.23 \\
(0.19)\end{array}$ & $\begin{array}{l}-0.27 \\
(0.19)\end{array}$ & - \\
\hline Agric & - & - & - & $\begin{array}{l}0.56^{*} \\
(0.14)\end{array}$ & - & - & - \\
\hline Natres & - & - & - & - & $\begin{array}{l}-0.04 \\
(0.24)\end{array}$ & - & - \\
\hline Man & - & - & - & - & - & $\begin{array}{l}-0.59^{*} \\
(0.14)\end{array}$ & - \\
\hline$R^{2}$ & 0.63 & 0.64 & 0.64 & 0.64 & 0.64 & 0.64 & 0.49 \\
\hline
\end{tabular}

Fonte: Resultados da pesquisa

*Significativo ao nível de $5 \%$, teste unilateral.

Nota: $X_{i j}$ é a variável dependente (exportações). Os erros-padrão estão entre parênteses. Todas as variáveis (exceto as dummy) estão expressas em logaritmo natural. Estimativa utilizando o Método dos Quadrados Mínimos (MQO). Número de observações 804.

Nas Tabelas 2 e 3 são apresentados os resultados para os anos de 1994 e 2009, respectivamente. Foram escolhidos esses anos em razão de abordarem um período inicial e um período mais recente da constituição do MERCOSUL (os marcos desta pesquisa). Após essa análise comparativa, é apresentada a equação

\footnotetext{
${ }^{9}$ Assim, as variáveis intituladas população são variáveis-instrumento das variáveis PIBs. Isto é possível porque renda e população são fortemente correlacionadas para o conjunto de dados desta pesquisa. Por exemplo, a correlação entre $N_{i t} e Y_{i t}$ em 2009 foi de $94 \%$.
} 
com todas as variáveis utilizando os cinco pontos no tempo abordados na pesquisa (Tabela 4).

Primeiramente, pode-se destacar que os coeficientes para os PIBs ( $Y_{i t}$ e $Y_{j t}$ ), para a distância (Distij) e para o MERCOSUL são relativamente estáveis ao se compararem as sete equações estimadas. Além disso, todos esses coeficientes são significativos e têm os sinais esperados. Os intervalos de variação desses coeficientes nas sete equações são estreitos: $Y_{i t}$ varia de 1.05 a $1.14, Y_{j t}$ varia de 0.95 a 1.02, Dist $t_{i j}$ varia de -1.08 a -1.80 e Merc varia de 1.07 a 1.30. Os coeficientes dos PIBs e da distância são também consistentes com estimativas feitas por outros autores, em outros estudos, como por exemplo McCallum $(1995)^{10}$, que relata, em sua pesquisa, variações entre 1.15 e 1.36 para $Y_{i 1} 0.96 \mathrm{e}$ 1.09 para $Y_{j}$ e -1.23 e -1.52 para Dist $t_{i j}$

Tabela 3. Estimativas para os coeficientes da equação gravitacional para os fluxos comerciais entre os países-membros do MERCOSUL e seus principais parceiros comerciais - 2009

\begin{tabular}{|c|c|c|c|c|c|c|c|}
\hline \multirow[b]{2}{*}{$\begin{array}{c}\text { Var. } \\
\text { independente }\end{array}$} & \multicolumn{6}{|c|}{ Equação } & \\
\hline & 1 & 2 & 3 & 4 & 5 & 6 & \\
\hline$Y_{i t}$ & $\begin{array}{l}1.59^{*} \\
(0.21)\end{array}$ & $\begin{array}{l}1.59^{*} \\
(0.21)\end{array}$ & $\begin{array}{l}1.60^{*} \\
(0.21)\end{array}$ & $\begin{array}{l}1.63^{*} \\
(0.20)\end{array}$ & $\begin{array}{l}1.60^{*} \\
(0.21)\end{array}$ & $\begin{array}{l}1.60^{*} \\
(0.20)\end{array}$ & - \\
\hline$Y_{j t}$ & $\begin{array}{l}0.57^{*} \\
(0.08)\end{array}$ & $\begin{array}{l}0.60^{*} \\
(0.08)\end{array}$ & $\begin{array}{l}0.70^{*} \\
(0.10)\end{array}$ & $\begin{array}{l}0.69 * \\
(0.10)\end{array}$ & $\begin{array}{l}0.70^{*} \\
(0.10)\end{array}$ & $\begin{array}{l}0.67^{*} \\
(0.10)\end{array}$ & \\
\hline$N_{i t}$ & $\begin{array}{l}-0.39 \\
(0.22)\end{array}$ & $\begin{array}{l}-0.39 \\
(0.22)\end{array}$ & $\begin{array}{l}-0.39 \\
(0.22)\end{array}$ & $\begin{array}{l}-0.39 \\
(0.21)\end{array}$ & $\begin{array}{l}-0.39 \\
(0.22)\end{array}$ & $\begin{array}{l}-0.40 \\
(0.22)\end{array}$ & $\begin{array}{c}1.32^{*} \\
(0.04)\end{array}$ \\
\hline$N_{j t}$ & $\begin{array}{l}0.48^{*} \\
(0.08)\end{array}$ & $\begin{array}{l}0.46^{*} \\
(0.07)\end{array}$ & $\begin{array}{l}0.34^{*} \\
(0.09)\end{array}$ & $\begin{array}{l}0.37^{*} \\
(0.11)\end{array}$ & $\begin{array}{l}0.35^{*} \\
(0.11)\end{array}$ & $\begin{array}{l}0.36^{*} \\
(0.11)\end{array}$ & $\begin{array}{l}0.88^{*} \\
(0.04)\end{array}$ \\
\hline Dist $_{i j}$ & $\begin{array}{l}-1.85^{*} \\
(0.11)\end{array}$ & $\begin{array}{l}-1.58^{*} \\
(0.13)\end{array}$ & $\begin{array}{l}-1.57^{*} \\
(0.15)\end{array}$ & $\begin{array}{l}-1.64^{*} \\
(0.15)\end{array}$ & $\begin{array}{c}-1.57^{*} \\
(0.15)\end{array}$ & $\begin{array}{l}-1.65^{*} \\
(0.14)\end{array}$ & $\begin{array}{l}-1.36^{*} \\
(0.11)\end{array}$ \\
\hline Mercosul & - & $\begin{array}{l}1.05^{*} \\
(0.36)\end{array}$ & $\begin{array}{l}0.85^{*} \\
(0.36)\end{array}$ & $\begin{array}{l}0.87^{*} \\
(0.35)\end{array}$ & $\begin{array}{l}0.86^{*} \\
(0.36)\end{array}$ & $\begin{array}{l}0.82^{*} \\
(0.33)\end{array}$ & $\begin{array}{l}0.60^{*} \\
(0.30)\end{array}$ \\
\hline Nafta & - & - & $\begin{array}{l}-0.72^{*} \\
(0.31)\end{array}$ & $\begin{array}{l}-0.59^{*} \\
(0.31)\end{array}$ & $\begin{array}{l}-0.72 * \\
(0.31)\end{array}$ & $\begin{array}{l}-0.51 * \\
(0.31)\end{array}$ & - \\
\hline Ue & - & - & $\begin{array}{l}-0.40 \\
(0.26)\end{array}$ & $\begin{array}{l}-0.41 \\
(0.26)\end{array}$ & $\begin{array}{l}-0.41 \\
(0.26)\end{array}$ & $\begin{array}{l}-0.37 \\
(0.26)\end{array}$ & - \\
\hline Agric & - & - & - & $\begin{array}{l}0.84^{*} \\
(0.15)\end{array}$ & - & - & - \\
\hline Natres & - & - & - & & $\begin{array}{l}-0.18 \\
(0.29)\end{array}$ & - & - \\
\hline Man & - & - & - & & - & $\begin{array}{c}-1.07^{*} \\
(0.15)\end{array}$ & - \\
\hline$R^{2}$ & 0.63 & 0.63 & 0.63 & 0.65 & 0.63 & 0.65 & 0.56 \\
\hline
\end{tabular}

Fonte: Resultados da pesquisa

*Significativo ao nível de $5 \%$, teste unilateral.

Nota: $X_{i j}$ é a variável dependente (exportações). Os erros-padrão estão entre parênteses. Todas as variáveis (exceto as dummy) estão expressas em logaritmo natural. Estimativa utilizando o Método dos Quadrados Mínimos (MQO). Número de observações 916.

${ }^{10}$ É importante mencionar que a pesquisa desse autor também se refere a fluxo de comércio entre países. 
Outro ponto interessante é que os coeficientes das variáveis população, mesmo que não sejam muito estáveis ( $N_{i t}$ variou entre 0.07 e 1.12 e $N_{j t}$ variou entre 0.01 e 0.81), só foram significativas na Equação 7 e não tiveram sinal esperado em nenhum caso, principalmente no caso de $N_{i t}$ em que se espera que seja negativo, pois, com o aumento da população do país i, a tendência é que suas exportações diminuam para atender à demanda interna.

Aborda-se agora um dos pontos principais da análise, qual seja o coeficiente da variável dummy do MERCOSUL. Ele teve o sinal esperado e foi significativo em todos os casos, além de ter o valor relevante. $\mathrm{Na}$ Equação 2, esse coeficiente foi 1.30, o que significa que os países do MERCOSUL como um todo comercializavam 3,64 vezes mais $\left(e^{1,30}=3,64\right)^{11}$ entre si do que com o restante dos países da amostra no ano de 1994, coeteris paribus. Assim, o aumento de comércio intrarregional do MERCOSUL é calculado como 3,64.

Tabela 4. Estimativas para os coeficientes da equação gravitacional para os fluxos comerciais entre os países-membros do MERCOSUL e seus principais parceiros comerciais para o período de 1994/1998/2002/2006/2009

\begin{tabular}{cccccc}
\hline $\begin{array}{c}\text { Variável } \\
\text { independente }\end{array}$ & 1994 & 1998 & 2002 & 2006 & 2009 \\
\hline$Y_{i t}$ & $1.05^{*}$ & $1.40^{*}$ & $2.10^{*}$ & $1.65^{*}$ & $1.62^{*}$ \\
& $(0.15)$ & $(0.15)$ & $(0.19)$ & $(0.17)$ & $(0.20)$ \\
$Y_{j t}$ & $1.01^{*}$ & $0.79^{*}$ & $0.97^{*}$ & $0.79^{*}$ & $0.67^{*}$ \\
& $(0.06)$ & $(0.07)$ & $(0.07)$ & $(0.07)$ & $(0.10)$ \\
$N_{i t}$ & 0.15 & -0.18 & $-0.89^{*}$ & -0.33 & -0.39 \\
& $(0.15)$ & $(0.16)$ & $(0.18)$ & $(0.21)$ & $(0.21)$ \\
$N_{j t}$ & 0.02 & $0.14^{*}$ & 0.12 & $0.33^{*}$ & $0.37^{*}$ \\
& $(0.08)$ & $(0.05)$ & $(0.07)$ & $(0.08)$ & $(0.11)$ \\
Dist $t_{i j}$ & $-1.46^{*}$ & $-1.68^{*}$ & $-1.64^{*}$ & $-1.72^{*}$ & $-1.66^{*}$ \\
& $(0.12)$ & $(0.15)$ & $(0.17)$ & $(0.13)$ & $(0.14)$ \\
Mercosul & $1.13^{*}$ & $0.62^{*}$ & $1.18^{*}$ & $0.69^{*}$ & $0.86^{*}$ \\
& $(0.23)$ & $(0.22)$ & $(0.34)$ & $(0.24)$ & $(0.33)$ \\
Nafta & $-0.58^{*}$ & -0.13 & -0.05 & -0.11 & -0.51 \\
& $(0.28)$ & $(0.23)$ & $(0.25)$ & $(0.20)$ & $(0.36)$ \\
Ue & -0.29 & -0.02 & 0.07 & $-0.56^{*}$ & -0.38 \\
& $(0.21)$ & $(0.20)$ & $(0.24)$ & $(0.19)$ & $(0.26)$ \\
Agric & 0.23 & 0.37 & 0.25 & 0.37 & 0.18 \\
& $(0.19)$ & $(0.21)$ & $(0.21)$ & $(0.25)$ & $(0.21)$ \\
Natres & -0.19 & 0.03 & 0.28 & 0.41 & -0.51 \\
& $(0.28)$ & $(0.32)$ & $(0.32)$ & $(0.28)$ & $(0.36)$ \\
Man & $-0.45^{*}$ & $-0.74^{*}$ & $-0.61^{*}$ & $-0.57^{*}$ & $-0.99^{*}$ \\
$R^{2}$ & $(0.19)$ & $(0.22)$ & $(0.20)$ & $(0.24)$ & $(0.21)$ \\
\hline
\end{tabular}

Fonte: Resultados da pesquisa.

*Significativo ao nível de $5 \%$, teste unilateral.

Nota: $X_{i j}$ é a variável dependente (exportações). Os erros-padrão estão entre parênteses. Todas as variáveis (exceto as dummy) estão expressas em logaritmo natural. Estimativa utilizando o Método dos Quadrados Mínimos (MQO). Número de observações: 804 para 1994, 819 para 1998, 886 para 2002, 923 para 2006 e 916 para 2009.

\footnotetext{
${ }^{11}$ Retornando a fórmula do modelo original, sem logaritmo (ver equação 1).
} 
É interessante notar que o coeficiente da variável dummy da UE não foi significativo em 1994 em todas as equações, o que indica que o comércio dos países-membros do MERCOSUL com os países da UE não foi relevante nesse ano. Já o coeficiente da variável dummy do NAFTA foi menor que um, indicando que o aumento de comércio foi de cerca de $0.55\left(e^{-0.59}=0.55\right)$ em todos os casos. Portanto, a variável do MERCOSUL teve o maior coeficiente entre as variáveis dummy de integração econômica consideradas, e o aumento de comércio intrarregional foi significativo já no período de implementação do bloco (no ano de 1994). Quanto ao coeficiente das variáveis para os setores (agrícola, recursos naturais e manufaturados), apenas o setor agrícola teve valor positivo e foi significativo.

Os resultados para 2009 estão na Tabela 3. Os coeficientes das variáveis independentes desse ano aparentam ser maiores que os do ano de 1994. Os coeficientes das variáveis $Y_{i t} Y_{j t} N_{j t}$ e Dist $t_{i j}$ e da dummy do MERCOSUL são relativamente estáveis ao se compararem as sete equações estimadas. Além disso, todos esses coeficientes são significativos e têm os sinais esperados. Os intervalos de variação desses coeficientes nas sete equações também são estreitos: $Y_{i t}$ varia de 1.59 a $1.63, Y_{j t}$ varia de 0.57 a $0.70, N_{j t}$ varia de 0.34 a 0.88 , Dist $t_{i j}$ varia de 1.36 a -1.85 e Merc varia de 0.60 a 1.05. Interessante é que, para esse ano, o coeficiente da variável população do país i (entre as variáveis independentes) foi significativo apenas na Equação 7.

Abordando agora o coeficiente da variável dummy do MERCOSUL, apesar de ele ter o sinal esperado e ser significativo em todos os casos, teve valores menores que as equações de 1994. Esse coeficiente teve o valor mais expressivo na Equação 2, que foi de 1.05. Isso significa que os países do MERCOSUL, ao serem tomados como um todo, comercializavam 2.83 vezes mais $\left(e^{1,05}=2.83\right)$ entre si do que com o restante dos países da amostra no ano de 2009, coeteris paribus. Assim, o aumento de comércio intrarregional do MERCOSUL é calculado como 2.83. Isso confirma que o auge do comércio intrarregional do bloco foi realmente na sua fase inicial, entre 1992 e 1998.

Os coeficientes para as variáveis dummy UE e NAFTA foram negativos, e não significativos no caso da UE. O coeficiente da variável dummy do NAFTA foi menor que um, indicando que o aumento de comércio foi de $0.60\left(e^{-0.51}=0.60\right)$ na Equação 6.

Quanto aos coeficientes das variáveis dummy para os setores, os setores agrícola e manufaturados foram significativos, mas apenas agricultura teve valor positivo, mostrando que os produtos desse setor ainda foram predominantes na pauta de exportação dos países do MERCOSUL para todos os países da amostra em 2009. O coeficiente de Agric foi de 0.84, indicando que o aumento de comércio dos produtos desse setor foi de $2.30\left(e^{0.84}=2.30\right)$. Já o coeficiente de Man foi de -1.07 , o que significa que o aumento de comércio desse setor foi de $0.34\left(e^{-1.07}=0.34\right)$.

No estágio seguinte da análise, foram adicionadas seis variáveis dummy ao modelo gravitacional padrão ao mesmo tempo: uma dummy para o MERCOSUL, uma para o NAFTA, uma para a UE, uma para o setor agrícola, uma para o setor de recursos naturais, uma para o setor de manufaturados e, posteriormente, foram adicionadas dummies para os países separadamente - Brasil, Paraguai, Uruguai e 
Argentina. Essas dummies para os países representam o comércio do MERCOSUL com seus membros, de forma individual.

Como visto anteriormente, as dummies dos principais blocos explicam o aumento de comércio quando os países-membros do MERCOSUL comercializam com seus parceiros (comércio intrarregional), com os países que integram o NAFTA e, por fim, com os países que compõem a UE. Assim, portanto, o modelo gravitacional é utilizado aqui para analisar o comércio internacional (exportações) dos países-membros do MERCOSUL com os principais parceiros comerciais do bloco, de modo que o modelo isola os efeitos de renda e distância e captura um "efeito Mercosul", e, complementando, um "efeito NAFTA" e um "efeito UE" quando variáveis dummy são adicionadas ao modelo gravitacional original.

Recapitulando a Equação 5, o modelo utilizado é definido por:

$\ln X_{i j t}=\ln a_{0}+a_{1} \ln Y_{i t}+a_{2} \ln Y_{j t}+a_{3} \ln Y N_{i t}+a_{4} \ln Y N_{j t}+a_{5} \ln D i s t_{i j t}+$ $a_{6}$ Merc $+a_{7}$ Nafta $+a_{8} U e+a_{9}$ Set $+\ln e_{i j}$

Em que:

$X_{i j t}$ é o valor em dólares americanos correntes no período $t$ das exportações do país $i$ ao país j; $Y_{i t}$ é o valor nominal em dólares americanos correntes no período $t$ do Produto Interno Bruto (PIB) do país $i_{i} Y_{j t}$ é o valor nominal em dólares americanos correntes no período $t$ do PIB do país j; $N_{i t}$ é a população do país ino período $t, N_{j t}$ é a população do país j no período $t_{\text {, Dist }}$ é a distância entre as capitais do país i e do país j; Mercosul é uma variável dummy igual a 1 se o país é membro do Mercosul e 0 se aquele país não é membro; Nafta é uma variável dummyigual a 1 se o país é membro do NAFTA e 0 se aquele país não é membro; UE é uma variável dummy igual a 1 se o país é membro da UE e 0 se aquele país não é membro; agric é uma variável dummy igual a 1 se a principal commodity exportada deriva do setor agrícola e 0 se não deriva; natres é uma variável dummy igual a 1 se a principal commodity exportada deriva do setor de recursos naturais e 0 se não deriva; man é uma variável dummy igual a 1 se a principal commodity exportada deriva do setor de manufaturados e 0 se não deriva.

Os resultados dessa equação gravitacional foram gerados para todos os anos abordados no trabalho (1994, 1998, 2002, 2006 e 2009) e são apresentados na Tabela 4. Os coeficientes $Y_{i t} Y_{j t}$ e Dist $t_{i j}$ foram significativos e tiveram o sinal esperado para o ano de 1994. Além disso, esses coeficientes são consistentes com as estimativas de outros autores, como Aitken (1973), McCallum (1995) e Sá Porto (2002), por exemplo. Pormenorizando, o aumento de $1 \%$ no PIB do país i causa um aumento de 1,05\% nas exportações do país i para o país j. Já o aumento de $1 \%$ no PIB do país j causa um aumento de 1,01\% das exportações do país $\mathrm{i}$ para o país j. Já a variável distância teve um coeficiente de $-1,43$, o que mostra que o aumento de $1 \%$ na distância dos países da amostra, o comércio diminui $1,43 \%$. Quanto ao coeficiente de população $\left(N_{i}\right.$ e $\left.N_{j}\right)$, este não foi significativo no ano de 1994, mostrando que o aumento populacional dos países não interferiu diretamente no fluxo comercial.

O coeficiente da dummy para o MERCOSUL (Merc) foi significativo e seu valor foi igual a 1.13. Nesse caso, os países-membros do MERCOSUL como um todo comercializavam 3.07 vezes $\left(e^{1,13}=3.07\right.$ ) mais com os países do próprio bloco (comércio intrarregional) do que com outros países da amostra em 1994. O coeficiente da dummy para o NAFTA (Nafta) foi negativo e igual a - 0,58. Um coeficiente menor que -1 resulta em um aumento de comércio menor que uma 
unidade, o que quer dizer que, coeteris paribus, os países-membros comercializaram $0.56 \mathrm{vez}\left(e^{-0,58}=0.56\right)$ com os países do Nafta. De modo similar, o coeficiente para a UE foi negativo e não significativo para o ano de 1994.

Quanto aos coeficientes das dummies de setor, o efeito de gerar as três variáveis ao mesmo tempo é diferente das equações analisadas nas Tabelas 3 e 4, em que as variáveis foram geradas uma de cada vez (equações 4,5 e 6). No ano de 1994, apenas o coeficiente da variável do setor manufaturados foi significativo, no entanto teve valor negativo, mostrando que o aumento de comércio das commodities desse setor foi de $0.63\left(e^{-0,45}=0.63\right)$.

Em relação aos resultados para o ano de 1998, os coeficientes $Y_{i t} Y_{j t} N_{j t} \mathrm{e}$ Dist $t_{i j}$ foram significativos e tiveram o sinal esperado. Pormenorizando, o aumento de $1 \%$ no PIB do país i causa um aumento de 1,40\% nas exportações do país $\mathrm{i}$ para o país j. Já o aumento de $1 \%$ no PIB do país j causa um aumento de 0,79\% das exportações do país i para o país j. Já a variável distância teve um coeficiente de $-1,68$, o que mostra que o aumento de $1 \%$ na distância dos países da amostra, o comércio diminui $1,68 \%$. O coeficiente da variável população do país j $\left(N_{j}\right)$ foi de 0,14 , mostrando que um aumento de $1 \%$ da população do país j causa um aumento de $0,14 \%$ nas importações do país i. Quanto ao coeficiente de população $N_{i}$ este não foi significativo no ano de 1998.

O coeficiente da dummy para o MERCOSUL (Merc) foi significativo e seu valor foi menor que 1994, 0.62. Nesse caso, os países-membros do MERCOSUL como um todo comercializavam 1.85 vez $\left(e^{0,62}=1.85\right)$ mais com os países do próprio bloco (comércio intrarregional) do que com outros países da amostra em 1998, coeteris paribus. Os coeficientes das dummies do NAFTA (Nafta) e da UE (Ue) foram negativos e não significativos. Quanto aos coeficientes das variáveis dos setores, de modo similar ao ano de 1994, apenas o coeficiente de Man foi significativo, porém teve valor negativo, o que quer dizer que o aumento de comércio das commodities desse setor foi de $0.48\left(e^{-0,74}=0.48\right)$.

Quanto aos resultados para o ano de 2002, os coeficientes $Y_{i t}, Y_{j t}, N_{i t}$ e Dist foram significativos e tiveram o sinal esperado. Pormenorizando, o aumento de $1 \%$ no PIB do país i causa um aumento de 2,10\% nas exportações do país i para o país j. Já o aumento de $1 \%$ no PIB do país j causa um aumento de 0,97\% das exportações do país i para o país j. Já a variável distância teve um coeficiente de 1,64 , o que mostra que o aumento de $1 \%$ na distância dos países da amostra, o comércio diminui $1,64 \%$ neste ano. O coeficiente da variável população do país $\mathrm{j}$ $\left(N_{j}\right)$ foi de $-0,89$, mostrando que um aumento de $1 \%$ da população do país i causa a diminuição de $0,89 \%$ nas suas exportações, valor esperado, já que, com o aumento da população, o país se volta a atender à demanda interna. Quanto ao coeficiente de população $j_{i r}$ este não foi significativo no ano de 2002.

O coeficiente da dummy para o MERCOSUL (Merc) foi significativo e seu valor foi maior que o dos anos anteriores, 1.18. Neste caso, os países-membros do MERCOSUL como um todo comercializavam 3.22 vezes $\left(e^{1,18}=3.22\right)$ mais com os países do próprio bloco (comércio intrarregional) do que com outros países da amostra em 1998, coeteris paribus. Os coeficientes das dummies do NAFTA (Nafta) e da UE ( Ue) foram negativos e não significativos. Quanto aos coeficientes das variáveis dos setores, de modo similar ao ano de 1998, apenas o coeficiente de Man foi significativo, porém teve valor negativo (-0.61), o que quer dizer que o aumento de comércio das commodities desse setor foi de $0.54\left(e^{-0,61}=0.54\right)$. 
Os resultados para o ano de 2006 apontam que os coeficientes $Y_{i t} Y_{j t} N_{j t} \mathrm{e}$ Dist $_{i j}$ foram significativos e tiveram o sinal esperado. O coeficiente $Y_{i t}$ mostra que o aumento de $1 \%$ no PIB do país i causa um aumento de 1,65\% nas exportações do país i para o país j. Já o aumento de $1 \%$ no PIB do país j causa um aumento de $0,79 \%$ das exportações do país i para o país j. A variável distância teve um coeficiente de $-1,72$, o que mostra que com o aumento de $1 \%$ na distância dos países da amostra, o comércio diminui 1,68\%. Já o coeficiente da variável população do país j $\left(N_{j}\right)$ foi de 0,33 , mostrando que um aumento de $1 \%$ da população do país j causa um aumento de 0,33\% nas suas importações do país i. Quanto ao coeficiente de população $N_{i}$ este não foi significativo no ano de 2006.

O coeficiente da dummy para o MERCOSUL foi significativo e seu valor foi 0.69. Nesse caso, os países-membros do MERCOSUL como um todo comercializavam 1.98 vez $\left(e^{0,69}=1.98\right)$ mais com os países do próprio bloco do que com outros países da amostra em 2006, coeteris paribus. O coeficiente da variável Nafta foi negativo e não significativo. Já o coeficiente da variável Ue foi significativo nesse ano, mas com valor negativo $(-0.56)$, o que mostra que o comércio dos países-membros do MERCOSUL aumentou $0.57\left(e^{-0,56}=0.57\right)$ com os países da Ue.

Quanto aos coeficientes das variáveis dos setores, de modo similar aos anos anteriores, apenas o coeficiente de Man foi significativo, mas com valor negativo, o que quer dizer que o aumento de comércio das commodities desse setor foi de $0.56\left(e^{-0,57}=0.56\right)$.

Nos resultados para o ano de 2009, os coeficientes $Y_{i t} Y_{j t} N_{j t}$ e Dist $t_{i j}$ foram significativos e tiveram o sinal esperado. Interpretando o coeficiente $Y_{i t}$ o aumento de $1 \%$ no PIB do país i causa um aumento de $1,62 \%$ nas exportações do país $i$ para o país j. Já o aumento de $1 \%$ no PIB do país j causa um aumento de $0,67 \%$ das exportações do país i para o país j. A variável distância teve um coeficiente de - 1,66, o que mostra que com o aumento de $1 \%$ na distância dos países da amostra, o comércio diminui $1,66 \%$. Já o coeficiente da variável população do país j $\left(N_{j}\right)$ foi de 0,37 , mostrando que um aumento de $1 \%$ da população do país j causa um aumento de $0,33 \%$ nas suas importações do país i. O coeficiente de população $N_{i}$ não foi significativo no ano de 2009.

O coeficiente de Merc foi significativo e seu valor foi 0.86 . Nesse caso, os países-membros do MERCOSUL como um todo comercializavam 2.34 vezes $\left(e^{0,86}=2.34\right)$ mais com os países do próprio bloco do que com outros países da amostra em 2009, coeteris paribus. É importante destacar que esse resultado mostra que pode estar ocorrendo uma retomada do crescimento do comércio intrarregional, embora não tão relevante quanto no período de transição.

Os coeficientes das dummies do NAFTA (Nafta) e da UE (Ue) foram negativos e não significativos para esse ano. Quanto aos coeficientes das variáveis dos setores, de modo similar ao ano de 2006, apenas o coeficiente de Man foi significativo, porém teve valor negativo (-0.99), o que quer dizer que o aumento de comércio das commodities desse setor foi de apenas $0.37\left(e^{-0,99}=0.37\right)$.

Considerando o foco da pesquisa, fazendo uma análise geral do coeficiente da variável dummy do MERCOSUL, ele assumiu os seguintes valores: $1,05\left(e^{1,13}=\right.$ $3,07)$ em 1994; $0,62\left(e^{0,62}=1,85\right)$ em $1998 ; 1,18\left(e^{1,18}=1,85\right)$ em $2002 ; 0,69$ $\left(e^{0,69}=1,98\right)$ em 2006; e $0,86\left(e^{0,86}=2,34\right)$ em 2009. Assim sendo, o MERCOSUL teve os maiores coeficientes das variáveis dummy que se referem aos blocos 
econômicos (integração), tendo seu ápice em 2002, que refletiu o aumento do comércio entre os países-membros do bloco.

Vale lembrar também que esse resultado mostra que, apesar das políticas cambiais divergentes dos ditos principais parceiros comerciais do bloco, Brasil e Argentina (devido à introdução do câmbio flutuante no Brasil em 1999 e à manutenção do câmbio fixo na Argentina até final de 2001), houve esse relevante aumento do comércio intrarregional. Isso indica que nem mesmo essas divergências ou até nem mesmo a crise da Argentina em 2002 foram suficientes para reduzir esse comércio. Depois, no entanto, os reflexos dessa crise foram percebidos nos anos posteriores da análise.

A seguir, são apresentados os resultados para cada país-membro.

\subsection{Análise do modelo gravitacional para os países-membros}

Nessa seção, foi estimado o modelo gravitacional original, acrescido das variáveis dummy dos principais blocos econômicos (como na Equação 3 nas Tabelas 3 e 4) e, ainda, das variáveis dummy para cada país-membro do MERCOSUL. Relembrando a Equação 6, temos:

$\ln X_{i j t}=\ln a_{0}+a_{1} \ln Y_{i t}+a_{2} \ln Y_{j t}+a_{3} \ln Y N_{i t}+a_{4} \ln Y N_{j t}+a_{5} \ln D_{i s t_{i j t}}+$ $a_{6}$ Merc $+a_{7}$ Nafta $+a_{8} U e+a_{9}$ País $+\ln e_{i j}$

Em que, País assume Bra., Par., Uru. e Arg., e todas as outras variáveis são definidas tal qual a Equação 5, com exceção da variável dummy Set, que não foi incluída nesse momento. Isso assim deve ser devido ao fato de o seu efeito ser o mesmo do que o analisado nas Tabelas 3 e 4, já que essa é uma dummy aplicada para o comércio do bloco, como um todo. Novamente, esse é um caso em que a equação que foi rodada quatro vezes para cada ano abordado, uma vez com cada dummy - Bra (Brasil), Arg (Argentina), Par (Paraguai) e Uru (Uruguai), para analisar o efeito individual.

O coeficiente dessa variável País vai mostrar o efeito do comércio intrarregional sobre cada país-membro, refletindo o aumento de comércio. É interessante salientar que, estimando o modelo com as dummies para país e para os principais blocos de integração, é possível verificar o efeito conjunto dessas variáveis, observando a importância que teve o comércio com o bloco, bem como com cada país-membro, nos anos de 1994, 1998, 2002, 2006 e 2009.

Os resultados estão sumarizados na Tabela 5. Primeiramente, observa-se que os coeficientes para os PIBs $\left(Y_{i t}\right.$ e $Y_{j t}$ ) e para a distância (Distij) são relativamente estáveis e muito semelhantes com os coeficientes obtidos na Tabela 4. Os intervalos de variação desses coeficientes são estreitos no decorrer dos anos analisados: $Y_{i t}$ varia de 1,09 a 2,10, $Y_{j t}$ varia de 0,70 a 1,05 e Dist $t_{i j}$ varia de -1,46 a $-1,69$. Vale lembrar que os coeficientes dos PIBs e da distância são também consistentes com estimativas feitas por outros autores, como visto anteriormente.

Da mesma forma, os coeficientes das variáveis população, mesmo que não sejam muito instáveis $\left(N_{i t}\right.$ variou entre $-0,89$ e 0,11 e $N_{j t}$ variou entre -0,01 e $0,35)$, quase não foram significativas, só $N_{j t}$ foi significativa e teve o sinal esperado em alguns anos. Pode-se observar que o coeficiente dessa variável evoluiu no decorrer do período para todos os países-membros, o que revela que, embora pequeno (2009), ocorreu um aumento de 0,34\% das exportações do país i para o país j, quando a população do país j aumentou em $1 \%$. 
O coeficiente da variável Merc se comportou de modo interessante quando adicionada a variável País, já que essas duas variáveis são muito relacionadas (a variável dummy País faz parte da variável Merc, que engloba os quatro paísesmembros). Nesse caso, tende a ocorrer um desvio na importância, ou para uma variável ou para outra (Merc x País). No caso da inclusão da variável Bra, o coeficiente Merc foi mais expressivo em 2002, sendo 0.91, o que indica que os países-membros do MERCOSUL, como um todo, comercializavam 2.46 vezes $\left(e^{0,91}=2.46\right)$ mais com os países do próprio bloco do que com outros países da amostra.

Com a inclusão da variável $A r g$, de modo semelhante, o valor mais expressivo para o coeficiente de Merc foi em 2002, de 1,56. Isso significa que, nesse ano, os países-membros do MERCOSUL comercializavam 4,7 vezes $\left(e^{1,56}=\right.$ $4,7)$ mais com os países do próprio bloco do que com outros países da amostra. No caso da inclusão da variável Par, o valor mais expressivo de Merc foi 0,89, ocorrido também em 2002, o que mostra que os países-membros do MERCOSUL comercializavam 2,42 vezes $\left(e^{0,89}=2,42\right)$ mais com os países do próprio bloco do que com outros países.

Já com a inclusão da variável Uru, o coeficiente Merc teve seu valor mais expressivo em 1994, que foi de 1,28. Isso indica que os países-membros do MERCOSUL comercializavam 3,56 vezes $\left(e^{1,28}=3,56\right)$ mais com os países do próprio bloco do que com outros países.

Esses valores são compatíveis com os obtidos na Tabela 4, em que os valores mais expressivos para o coeficiente da variável Merc também foi em 1994 e 2002, respectivamente. Após uma queda desse coeficiente em 2006, que pode ser atribuída aos reflexos da crise argentina de 2002, observa-se que, embora em menor grau, esse coeficiente evoluiu entre 2006 a 2009 (com exceção do caso do Paraguai).

Em relação ao coeficiente da dummy País, obteve-se um comportamento diferenciado, mostrando que os efeitos do comércio intrabloco se deram de forma desigual. Pormenorizando, no caso da dummy Bras, ela teve coeficientes significativos e expressivos em 1994 e 1998, mostrando que o comércio do MERCOSUL com o Brasil foi muito relevante nesses anos. Os valores foram 1.46 em 1994 e 1.09 em 1998, mostrando que o comércio dos países-membros do MERCOSUL com o Brasil foi 4.2 vezes $\left(e^{1,46}=4.2\right)$ maior do que com o restante da amostra em 1994, e 2.9 vezes $\left(e^{1,09}=2.9\right)$ maior em 1998. Já nos anos posteriores os coeficientes não foram significativos.

Para a dummy Arg, o coeficiente desta variável só não foi significativo em 2006, no entanto, em todos os anos obteve sinal negativo. Isso indica que o comércio do MERCOSUL com a Argentina não foi muito relevante nesses anos. $O$ melhor índice foi em 2002, de -1.10, que mostra que os países do MERCOSUL comercializavam $0.33 \mathrm{vez}\left(e^{-1,10}=0.33\right)$ mais com a Argentina do que com 0 restante dos países da amostra.

A dummy Par obteve um coeficiente significativo em quase todos os anos abordados (exceto 2006), e apresentou sinal positivo no período. Os valores mais expressivos foram justamente em 1994 e 2009 (marcos da pesquisa), e foram de 1.17 e 1.22, respectivamente. Isso mostra que, em 1994, o comércio dos paísesmembros do MERCOSUL com o Paraguai foi 3.19 vezes $\left(e^{1,17}=3.19\right)$ maior do que com o restante da amostra. $\mathrm{E}$, em 2009 , foi 3.35 vezes $\left(e^{1,22}=3.35\right)$ maior. 
Esse resultado mostra que o comércio entre os países-membros do MERCOSUL e o Paraguai é muito relevante e que, apesar de terem existido anos de declínio, no último ano da análise ele mostrou evolução (2009).

O coeficiente da dummy Uru foi significativo somente em 1994, porém, obteve sinal negativo, o que indica que o comércio do MERCOSUL com o Uruguai não foi muito relevante nos anos analisados. Seu valor foi -0.86 , o que mostra que, em 1994, o comércio dos países-membros do MERCOSUL com o Uruguai foi $0.42 \mathrm{vez}\left(e^{-0,86}=0.42\right)$ maior do que com o restante dos países da amostra.

Interessante é observar que, embora com sinal negativo, a variável dummy da UE obteve valor significativo em 2006 para os quatro países, e obteve um intervalo de variação muito pequeno: -0.51 a -0.57 , o que mostra que, nesse ano, o MERCOSUL comercializou 0.60 vez $\left(e^{-0,51}=0.60\right)$ mais com os países da UE do que com os países do restante da amostra (considerando o melhor índice). E o coeficiente de Nafta foi significativo no período inicial e no período final da análise, nos quatro casos, variando de -0.58 a -0.77 , o que indica que o MERCOSUL comercializou 0.56 vez $\left(e^{-0,51}=0.56\right)$ mais com os países da UE do que com os países do restante da amostra em 1994 (considerando também o melhor índice). 
Desenvolvimento do Mercosul: uma avaliação dos fluxos de comércio

Tabela 5. Estimativas para os coeficientes da equação gravitacional para os fluxos comerciais entre os países-membros do MERCOSUL e seus principais parceiros comerciais, incluindo uma dummy para País

\begin{tabular}{|c|c|c|c|c|c|c|c|c|c|c|c|c|c|c|c|c|c|c|c|c|}
\hline & \multicolumn{5}{|c|}{ Brasil } & \multicolumn{5}{|c|}{ Argentina } & \multicolumn{5}{|c|}{ Paraguai } & \multicolumn{5}{|c|}{ Uruguai } \\
\hline Var. Ind. & 1994 & 1998 & 2002 & 2006 & 2009 & 1994 & 1998 & 2002 & 2006 & 2009 & 1994 & 1998 & 2002 & 2006 & 2009 & 1994 & 1998 & 2002 & 2006 & 2009 \\
\hline$Y_{i t}$ & $\begin{array}{l}1.10^{*} \\
(0.15)\end{array}$ & $\begin{array}{l}1.48^{*} \\
(0.15)\end{array}$ & $\begin{array}{l}2.09^{*} \\
(0.19)\end{array}$ & $\begin{array}{l}1.70^{*} \\
(0.17)\end{array}$ & $\begin{array}{l}1.60^{*} \\
(0.21)\end{array}$ & $\begin{array}{l}1.09^{*} \\
(0.15)\end{array}$ & $\begin{array}{l}1.48^{*} \\
(0.15)\end{array}$ & $\begin{array}{l}2.09^{*} \\
(0.18)\end{array}$ & $\begin{array}{l}1.70^{*} \\
(0.17)\end{array}$ & $\begin{array}{l}1.60^{*} \\
(0.21)\end{array}$ & $\begin{array}{l}1.09^{*} \\
(0.16)\end{array}$ & $\begin{array}{l}1.47^{*} \\
(0.16)\end{array}$ & $\begin{array}{l}2.07^{*} \\
(0.19)\end{array}$ & $\begin{array}{l}1.69^{*} \\
(0.17)\end{array}$ & $\begin{array}{l}1.57^{*} \\
(0.21)\end{array}$ & $\begin{array}{l}1.09^{*} \\
(0.16)\end{array}$ & $\begin{array}{l}1.49^{*} \\
(0.15)\end{array}$ & $\begin{array}{l}2.10^{*} \\
(0.19)\end{array}$ & $\begin{array}{l}1.72^{*} \\
(0.17)\end{array}$ & $\begin{array}{l}1.60^{*} \\
(0.21)\end{array}$ \\
\hline$Y_{j t}$ & $\begin{array}{l}1.02^{*} \\
(0.06)\end{array}$ & $\begin{array}{l}0.79 * \\
(0.07)\end{array}$ & $\begin{array}{l}0.99^{*} \\
(0.07)\end{array}$ & $\begin{array}{l}0.81^{*} \\
(0.07)\end{array}$ & $\begin{array}{l}0.70^{*} \\
(0.10)\end{array}$ & $\begin{array}{l}1.05^{*} \\
(0.06)\end{array}$ & $\begin{array}{l}0.81^{*} \\
(0.07)\end{array}$ & $\begin{array}{l}1.02^{*} \\
(0.07)\end{array}$ & $\begin{array}{l}0.83^{*} \\
(0.07)\end{array}$ & $\begin{array}{l}0.72^{*} \\
(0.10)\end{array}$ & $\begin{array}{l}1.05^{*} \\
(0.06)\end{array}$ & $\begin{array}{l}0.82^{*} \\
(0.07)\end{array}$ & $\begin{array}{l}1.03^{*} \\
(0.08)\end{array}$ & $\begin{array}{l}0.84^{*} \\
(0.07)\end{array}$ & $\begin{array}{l}0.74^{*} \\
(0.10)\end{array}$ & $\begin{array}{l}1.03^{*} \\
(0.06)\end{array}$ & $\begin{array}{l}0.80^{*} \\
(0.07)\end{array}$ & $\begin{array}{l}1.00^{*} \\
(0.07)\end{array}$ & $\begin{array}{l}0.82^{*} \\
(0.07)\end{array}$ & $\begin{array}{l}0.70^{*} \\
(0.10)\end{array}$ \\
\hline$N_{i t}$ & $\begin{array}{c}0.11 \\
(0.15)\end{array}$ & $\begin{array}{l}-0.25 \\
(0.16)\end{array}$ & $\begin{array}{l}0.88^{*} \\
(0.18)\end{array}$ & $\begin{array}{l}-0.39 \\
(0.21)\end{array}$ & $\begin{array}{l}-0.39 \\
(0.22)\end{array}$ & $\begin{array}{c}0.12 \\
(0.15)\end{array}$ & $\begin{array}{c}-0.26 \\
(0.16)\end{array}$ & $\begin{array}{l}0.89^{*} \\
(0.18)\end{array}$ & $\begin{array}{c}-0.39 \\
(0.21)\end{array}$ & $\begin{array}{c}-0.39 \\
(0.22)\end{array}$ & $\begin{array}{c}0.12 \\
(0.15)\end{array}$ & $\begin{array}{l}-0.25 \\
(0.16)\end{array}$ & $\begin{array}{l}0.86^{*} \\
(0.18)\end{array}$ & $\begin{array}{c}-0.38 \\
(0.21)\end{array}$ & $\begin{array}{l}-0.36 \\
(0.22)\end{array}$ & $\begin{array}{c}0.12 \\
(0.15)\end{array}$ & $\begin{array}{l}-0.26 \\
(0.16)\end{array}$ & $\begin{array}{l}0.89^{*} \\
(0.18)\end{array}$ & $\begin{array}{l}0.41^{*} \\
(0.21)\end{array}$ & $\begin{array}{l}-0.39 \\
(0.22)\end{array}$ \\
\hline$N_{j t}$ & $\begin{array}{l}-0.01 \\
(0.08)\end{array}$ & $\begin{array}{l}0.13^{*} \\
(0.05)\end{array}$ & $\begin{array}{c}0.10 \\
(0.07)\end{array}$ & $\begin{array}{l}0.31^{*} \\
(0.08)\end{array}$ & $\begin{array}{l}0.34^{*} \\
(0.11)\end{array}$ & $\begin{array}{c}0.01 \\
(0.08)\end{array}$ & $\begin{array}{l}0.14^{*} \\
(0.05)\end{array}$ & $\begin{array}{c}0.10 \\
(0.07)\end{array}$ & $\begin{array}{l}0.32^{*} \\
(0.08)\end{array}$ & $\begin{array}{l}0.35^{*} \\
(0.11)\end{array}$ & $\begin{array}{c}0.01 \\
(0.08)\end{array}$ & $\begin{array}{l}0.14^{*} \\
(0.05)\end{array}$ & $\begin{array}{c}0.09 \\
(0.07)\end{array}$ & $\begin{array}{l}0.30^{*} \\
(0.08)\end{array}$ & $\begin{array}{l}0.32^{*} \\
(0.11)\end{array}$ & $\begin{array}{c}-0.01 \\
(0.08)\end{array}$ & $\begin{array}{l}0.14^{*} \\
(0.05)\end{array}$ & $\begin{array}{c}0.10 \\
(0.07)\end{array}$ & $\begin{array}{l}0.32^{*} \\
(0.08)\end{array}$ & $\begin{array}{l}0.35^{*} \\
(0.11)\end{array}$ \\
\hline Dist $_{i j}$ & $\begin{array}{c}-1.47^{*} \\
(0.12)\end{array}$ & $\begin{array}{c}- \\
1.69 * \\
(0.15)\end{array}$ & $\begin{array}{l}1.67^{*} \\
(0.17)\end{array}$ & $\begin{array}{c}- \\
1.64^{*} \\
(0.13)\end{array}$ & $\begin{array}{c}- \\
1.59^{*} \\
(0.14)\end{array}$ & $\begin{array}{c}-1.55^{*} \\
(0.13)\end{array}$ & $\begin{array}{c}1.68^{*} \\
(0.16)\end{array}$ & $\begin{array}{c}- \\
1.72^{*} \\
(0.16)\end{array}$ & $\begin{array}{c}- \\
1.69^{*} \\
(0.12)\end{array}$ & $\begin{array}{c}- \\
1.64^{*} \\
(0.14)\end{array}$ & $\begin{array}{c}- \\
1.46^{*} \\
(0.12)\end{array}$ & $\begin{array}{c}- \\
1.65^{*} \\
(0.15)\end{array}$ & $\begin{array}{c}- \\
1.67^{*} \\
(0.17)\end{array}$ & $\begin{array}{c}- \\
1.64^{*} \\
(0.13)\end{array}$ & $\begin{array}{c}- \\
1.58^{*} \\
(0.14)\end{array}$ & $\begin{array}{c}- \\
1.47^{*} \\
(0.13)\end{array}$ & $\begin{array}{c}- \\
1.64^{*} \\
(0.16)\end{array}$ & $\begin{array}{c}- \\
1.63^{*} \\
(0.18)\end{array}$ & $\begin{array}{c}- \\
1.62^{*} \\
(0.13)\end{array}$ & $\begin{array}{c}- \\
1.56^{*} \\
(0.15)\end{array}$ \\
\hline Mercosul & $\begin{array}{l}0.74^{*} \\
(0.23)\end{array}$ & $\begin{array}{c}0.32 \\
(0.29)\end{array}$ & $\begin{array}{l}0.91^{*} \\
(0.42)\end{array}$ & $\begin{array}{l}0.63^{*} \\
(0.33)\end{array}$ & $\begin{array}{l}0.64^{*} \\
(0.35)\end{array}$ & $\begin{array}{l}1.40^{*} \\
(0.23)\end{array}$ & $\begin{array}{l}0.91^{*} \\
(0.25)\end{array}$ & $\begin{array}{l}1.56^{*} \\
(0.36)\end{array}$ & $\begin{array}{l}1.01^{*} \\
(0.29)\end{array}$ & $\begin{array}{l}1.16^{*} \\
(0.41)\end{array}$ & $\begin{array}{l}0.88^{*} \\
(0.25)\end{array}$ & $\begin{array}{c}0.49 \\
(0.27)\end{array}$ & $\begin{array}{l}0.89^{*} \\
(0.38)\end{array}$ & $\begin{array}{l}0.60^{*} \\
(0.30)\end{array}$ & $\begin{array}{c}0.56 \\
(0.40)\end{array}$ & $\begin{array}{l}1.28^{*} \\
(0.25)\end{array}$ & $\begin{array}{l}0.78^{*} \\
(0.28)\end{array}$ & $\begin{array}{l}1.08^{*} \\
(0.34)\end{array}$ & $\begin{array}{l}0.60^{*} \\
(0.25)\end{array}$ & $\begin{array}{l}0.83^{*} \\
(0.39)\end{array}$ \\
\hline Nafta & $\begin{array}{l}-0.58^{*} \\
(0.27)\end{array}$ & $\begin{array}{l}-0.23 \\
(0.23)\end{array}$ & $\begin{array}{c}-0.18 \\
(0.25)\end{array}$ & $\begin{array}{l}-0.26 \\
(0.20)\end{array}$ & $\begin{array}{c}- \\
0.72^{*} \\
(0.31)\end{array}$ & $\begin{array}{l}-0.65^{*} \\
(0.27)\end{array}$ & $\begin{array}{c}-0.26 \\
(0.23)\end{array}$ & $\begin{array}{l}-0.24 \\
(0.25)\end{array}$ & $\begin{array}{c}-0.29 \\
(0.19)\end{array}$ & $\begin{array}{c}- \\
0.76^{*} \\
(0.31)\end{array}$ & $\begin{array}{c}- \\
0.64^{*} \\
(0.27)\end{array}$ & $\begin{array}{c}-0.27 \\
(0.23)\end{array}$ & $\begin{array}{l}-0.25 \\
(0.25)\end{array}$ & $\begin{array}{c}-0.31 \\
(0.20)\end{array}$ & $\begin{array}{c}- \\
0.77^{*} \\
(0.31)\end{array}$ & $\begin{array}{c}- \\
0.60^{*} \\
(0.27)\end{array}$ & $\begin{array}{c}-0.24 \\
(0.23)\end{array}$ & $\begin{array}{l}-0.20 \\
(0.25)\end{array}$ & $\begin{array}{c}-0.28 \\
(0.20)\end{array}$ & $\begin{array}{c}- \\
0.72^{*} \\
(0.31)\end{array}$ \\
\hline Ue & $\begin{array}{l}-0.27 \\
(0.19)\end{array}$ & $\begin{array}{l}-0.06 \\
(0.20)\end{array}$ & $\begin{array}{c}0.10 \\
(0.23)\end{array}$ & $\begin{array}{c}- \\
0.55^{*} \\
(0.18)\end{array}$ & $\begin{array}{l}-0.42 \\
(0.26)\end{array}$ & $\begin{array}{l}-0.20 \\
(0.19)\end{array}$ & $\begin{array}{c}0.09 \\
(0.20)\end{array}$ & $\begin{array}{c}0.14 \\
(0.23)\end{array}$ & $\begin{array}{l}0.51^{*} \\
(0.18)\end{array}$ & $\begin{array}{c}-0.35 \\
(0.26)\end{array}$ & $\begin{array}{l}-0.21 \\
(0.19)\end{array}$ & $\begin{array}{c}0.08 \\
(0.20)\end{array}$ & $\begin{array}{c}0.12 \\
(0.23)\end{array}$ & $\begin{array}{l}0.57^{*} \\
(0.18)\end{array}$ & $\begin{array}{l}-0.41 \\
(0.26)\end{array}$ & $\begin{array}{c}-0.26 \\
(0.19)\end{array}$ & $\begin{array}{c}0.07 \\
(0.20)\end{array}$ & $\begin{array}{c}0.12 \\
(0.23)\end{array}$ & $\begin{array}{l}0.54^{*} \\
(0.18)\end{array}$ & $\begin{array}{l}-0.40 \\
(0.26)\end{array}$ \\
\hline Bra & $\begin{array}{l}1.46^{*} \\
(0.45)\end{array}$ & $\begin{array}{l}1.09^{*} \\
(0.34)\end{array}$ & $\begin{array}{c}0.71 \\
(0.40)\end{array}$ & $\begin{array}{c}0.29 \\
(0.39)\end{array}$ & $\begin{array}{c}0.63 \\
(0.80)\end{array}$ & & & & & & & & & & & & & & & \\
\hline $\operatorname{Arg}$ & & & & & & $\begin{array}{c}-1.72^{*} \\
(0.41)\end{array}$ & $\begin{array}{l}1.10^{*} \\
(0.47)\end{array}$ & $\begin{array}{l}2.06^{*} \\
(0.52)\end{array}$ & $\begin{array}{c}-1.44 \\
(0.48)\end{array}$ & $\begin{array}{l}1.64^{*} \\
(0.57)\end{array}$ & & & & & & & & & & \\
\hline Par & & & & & & & & & & & $\begin{array}{l}1.17^{*} \\
(0.31)\end{array}$ & $\begin{array}{l}0.80^{*} \\
(0.39)\end{array}$ & $\begin{array}{l}1.03^{*} \\
(0.41)\end{array}$ & $\begin{array}{c}0.51 \\
(0.41)\end{array}$ & $\begin{array}{l}1.22^{*} \\
(0.58)\end{array}$ & & & & & \\
\hline Uru & & & & & & & & & & & & & & & & $\begin{array}{c}- \\
0.86^{*} \\
(0.43)\end{array}$ & $\begin{array}{l}-0.25 \\
(0.44)\end{array}$ & $\begin{array}{c}0.40 \\
(0.68)\end{array}$ & $\begin{array}{c}0.69 \\
(0.68)\end{array}$ & $\begin{array}{c}0.09 \\
(0.66)\end{array}$ \\
\hline$R^{2}$ & 0.65 & 0.64 & 0.64 & 0.67 & 0.63 & 0.64 & 0.64 & 0.65 & 0.68 & 0.64 & 0.64 & 0.64 & 0.64 & 0.67 & 0.64 & 0.64 & 0.64 & 0.64 & 0.67 & 0.63 \\
\hline
\end{tabular}

Fonte: Resultados da pesquisa.

*Significativo ao nível de $5 \%$, teste unilateral.

Nota: $X_{i j}$ é a variável dependente (exportações). Os erros-padrão estão entre parênteses. Todas as variáveis (exceto as dummy) estão expressas em logaritmo natural. Estimativa utilizando o Método dos Quadrados Mínimos (MQO). Número de observações: 804 para 1994, 819 para 1998,886 para 2002,923 para 2006 e 916 para 2009. 
Nesse contexto, torna-se relevante abordar as exportações totais intrabloco, que são ilustradas no Gráfico 1. Foram escolhidos três dos cinco pontos no tempo analisado na pesquisa, 1994, 2002 e 2009. Pode-se observar que houve uma relevante evolução no comércio intrabloco. As exportações brasileiras destinadas ao MERCOSUL mais que dobraram no período analisado, atingindo um crescimento de $267 \%$. No entanto, os principais destinos das exportações do Brasil são China e Estados Unidos.

Gráfico 1. Exportações dos países-membros para o MERCOSUL, 1994/2002/2009

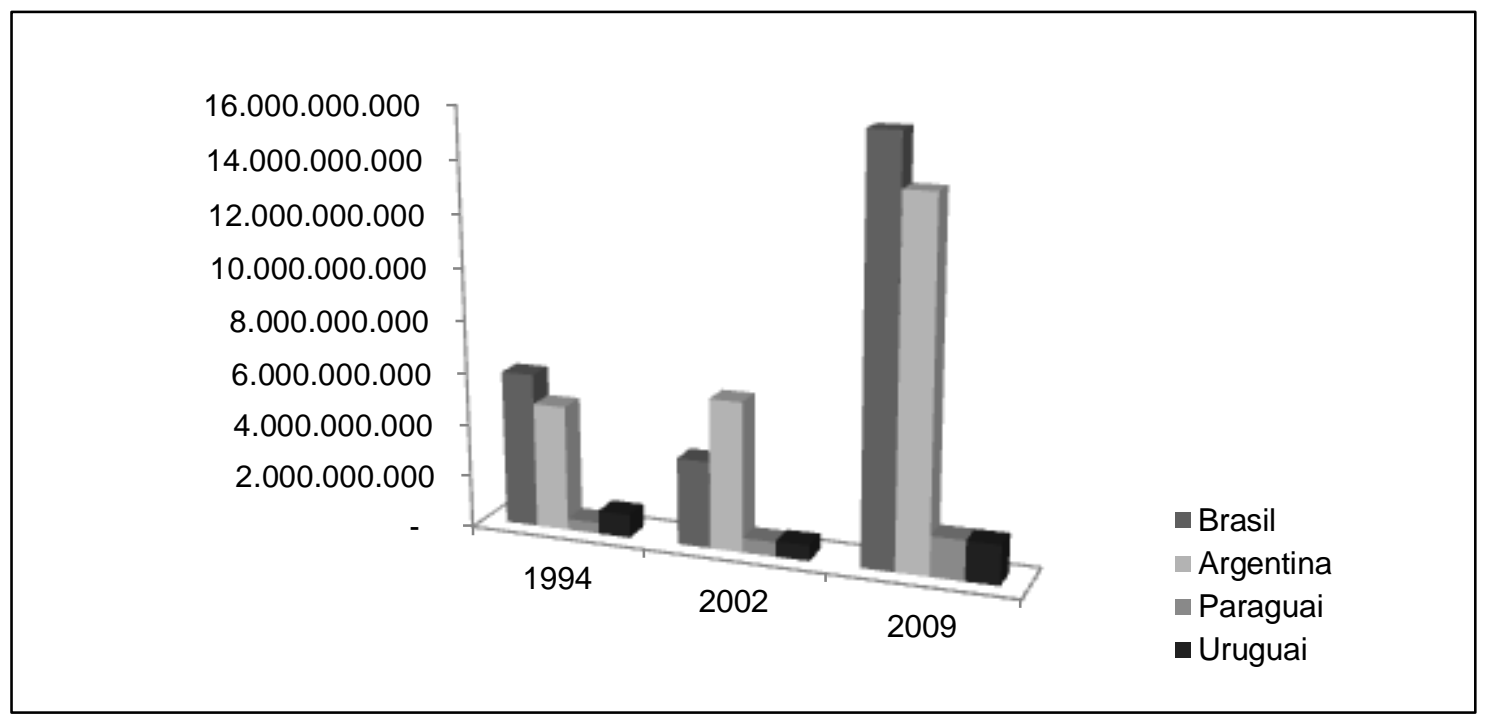

Fonte: Dados da United Nations Commodity Trade (2010).

As exportações argentinas para a América Latina vêm crescendo significantemente nas últimas décadas, ao ponto de que os países do MERCOSUL, principalmente o Brasil, terem sido os principais destinos de suas exportações em 2009. A evolução das exportações da Argentina foi de cerca de 287\% entre 1994 e 2009.

Cabe destacar que as evoluções no período foram as seguintes: $267 \%$ nas exportações brasileiras, 287\% nas exportações argentinas, 360\% nas exportações paraguaias e, aproximadamente, $170 \%$ nas exportações do Uruguai. Destaque deve ser dado para o Paraguai, que, embora seja a menor economia do bloco, teve o maior crescimento no comércio em termos percentuais.

Observando-se o Gráfico 1, o Paraguai atingiu praticamente o mesmo patamar das exportações do Uruguai. Ele teve esse relevante crescimento de suas exportações destinadas ao MERCOSUL na medida em que seus destinos de exportação sofriam uma grande alteração. Interessante é mencionar que, segundo dados da Comissão Econômica das Nações Unidas para a América Latina - CEPAL (2011), ao longo das décadas de 1970 e 1980, o principal destino das exportações paraguaias era a UE. Depois, contudo, a partir da década de 1990, as exportações para o continente europeu começaram a cair drasticamente e passaram a ser destinadas aos demais países do MERCOSUL, países que, em 2009, se tornaram os principais destinos de suas exportações. O aumento dessas exportações foi de mais de 360\% entre 1994 e 2009. 
Semelhante ao Paraguai, o Uruguai também experimentou uma mudança notável no destino de suas exportações ao longo o período analisado. As exportações destinadas ao MERCOSUL aumentaram de forma relevante. Por exemplo, em 1998 representavam 55,33\% das exportações totais do país. No período de análise, o aumento nas suas exportações intrabloco foi de cerca de $170 \%$. Em 2009, os países-membros foram os principais destinos de suas exportações.

Em suma, pode-se verificar que a criação do bloco surtiu efeitos sobre a economia de todos eles. Em muitos dos casos o padrão de exportações segundo o destino se alterou de maneira significativa, impactando diretamente no perfil das suas exportações.

Enquanto projeto de liberalização comercial e de integração de atividades econômicas de âmbito regional, o MERCOSUL é uma pequena parte do comércio, dos intercâmbios mantidos pelo Brasil com o exterior. Essa parte cresceu muito no curso dos primeiros dez anos desde o Tratado de Assunção, passando de menos de $5 \%$ dos intercâmbios externos para cerca de $14 \%$. No entanto, não se pode afirmar que esse crescimento do comércio estaria ausente se não existisse a formação do bloco, mas é certo que esse processo ajudou nesse crescimento. $O$ que não se pode perder de vista é que, como toda questão econômica de acordos comerciais, sempre existirão custos e benefícios envolvidos.

$\mathrm{Na}$ próxima seção são apresentadas as últimas considerações, que sumarizam este artigo.

\section{CONSIDERAÇÕES}

Apesar de tantas alternativas e de tantos organismos criados na intenção de se consolidar o processo integracionista, depois de 20 anos, os desafios continuam os mesmos. Já se sabe que até mesmo os maiores países latinos precisam do peso econômico e político de outros países, pois um país em desenvolvimento pode, de certo modo, ter menos representatividade diante das negociações mundiais. As autoridades e representantes do comércio internacional dos países-membros deveriam avaliar com mais rigor se os benefícios de um Mercado Comum superam os custos de uma coordenação macroeconômica. A julgar pelo tempo de duração do processo sem avanços muito significativos, os custos podem estar muito maiores que os ganhos.

Inferindo os dados a partir do modelo gravitacional, a pretensão do trabalho foi analisar os efeitos do fluxo de comércio intrarregional sobre os paísesmembros. Foi utilizado um modelo gravitacional-padrão, um modelo que isola os efeitos de renda e de distância de modo a concentrar a análise nos efeitos que um acordo de integração econômica pode ter nas economias participantes e em suas regiões. Foram utilizadas equações gravitacionais básicas (a equação gravitacionalpadrão adicionada às variáveis dummy de integração econômica, bem como uma dummy para os setores da economia e uma para cada país-membro), e os dados foram seccionais (cross section).

Os resultados obtidos mostram que os efeitos do comércio intrabloco nas economias dos países-membros como um todo foram bastante significativos no período 1994-2009, efeitos esses que foram muito maiores do que o de outros 
agrupamentos econômicos regionais muito relevantes para suas economias, tais como o Nafta ou a UE.

Em 1994, o coeficiente da variável dummy do MERCOSUL foi 1.30, o que significa que os países do MERCOSUL como um todo comercializavam 3,64 vezes mais entre si do que com o restante dos países da amostra. O coeficiente da dummy da UE não foi relevante nesse ano e o coeficiente da variável dummy do NAFTA foi menor que um, indicando que o aumento de comércio dos paísesmembros com esse bloco foi de cerca de 0,55.

Já em 2009, o coeficiente da variável dummy do MERCOSUL foi um pouco menor, de 1.05. Isso significa que os países do MERCOSUL como um todo comercializavam 2,83 vezes mais entre si do que com o restante dos países. Logo, - MERCOSUL obteve os maiores coeficientes (e os maiores aumentos de comércio), entre todos os esquemas de integração regionais relevantes para os países-membros.

Quando considerada a análise dos setores, os coeficientes das dummies dos setores agrícola e manufaturados foram significativos, mas apenas agricultura teve valor positivo, mostrando que os produtos desse setor ainda foram predominantes na pauta de exportação dos países do MERCOSUL para todos os países da amostra, tanto em 1994, quanto em 2009. Mesmo com o amadurecimento histórico dos parques industriais dos países envolvidos nesse processo integracionista, principalmente do Brasil e Argentina, a agricultura continua sendo setor de vital importância nas relações comerciais dos países. Vale considerar também que, no período abarcado na análise, em função de crises internas no caso argentino, ou do próprio desenvolvimento acima da média da agricultura no caso brasileiro, esses países viveram um processo de desindustrialização. Processo que continua se fazendo presente no desenvolvimento de ambos, embora com outros agravantes, como a questão cambial, por exemplo.

Confirmando a hipótese levantada antes da obtenção dos resultados, o efeito do comércio intrarregional se deu de forma desigual quando considerados os países-membros de forma individual. No caso do coeficiente da dummy do Brasil, os valores significativos e mais expressivos foram 1,46 em 1994 e 1,09 em 1998, mostrando que o comércio dos países-membros do MERCOSUL com o Brasil foi 4,2 vezes maior do que com o restante da amostra em 1994, e 2,9 vezes maior em 1998.

Quanto à dummy para a Argentina, o coeficiente dessa variável só não foi significativo em 2006, no entanto em todos os anos obteve sinal negativo. Isso indica que o comércio do MERCOSUL com a Argentina não evoluiu muito nesses anos. O melhor índice foi em 2002, de -1,10, que mostra que os outros paísesmembros comercializavam 0,33 vez mais com a Argentina do que com o restante dos países da amostra.

No caso do Paraguai, esse coeficiente foi significativo em quase todos os anos abordados, com exceção de 2006, e obteve sempre sinal positivo no período. O valor mais expressivo foi 1,22, justamente em 2009. Isso mostra que ,naquele ano, o comércio dos países-membros com o Paraguai foi 3,35 vezes maior do que com o restante da amostra. Isso confirma o aumento da importância do MERCOSUL para a economia paraguaia. Em 2009, os países do MERCOSUL foram os principais destinos das exportações desse país. 
Já o coeficiente da dummy do Uruguai só foi significativo em 1994, porém obteve sinal negativo, o que indica que o comércio do MERCOSUL com o Uruguai não foi muito relevante no período analisado. Seu valor foi $-0,86$ e que mostra o aumento de comércio entre eles foi 0,42 vez maior do que com o restante dos países da amostra.

Por fim, pode-se concluir que, mesmo que os efeitos do bloco no âmbito do comércio não sejam uniformes para os estados partes, a constituição do MERCOSUL surtiu efeitos significativos sobre o padrão de exportações dos seus integrantes, pois, de modo geral, eles experimentaram um aumento significativo das suas exportações intrabloco durante o período analisado.

Entretanto, não é possível considerar que a formação de um bloco subregional seja a única alternativa de promoção dos mercados envolvidos, dada a instabilidade que os países-membros vivenciaram principalmente durante os anos de crise. Conforme Cardoso et al. (2009), em uma pesquisa feita para verificar o desempenho do setor externo do MERCOSUL, isso se confirma, pois, os índices obtidos para o MERCOSUL no período de 1995-2006 mostraram que os paísesmembros quase sempre apresentaram alta vulnerabilidade aos choques externos, 0 que culmina em desequilíbrios internos. Entre várias necessidades, é compreendido que os países-membros precisem estabelecer claramente quais os objetivos favoráveis para suas economias e, se for o caso, estabelecer uma coordenação macroeconômica conjunta para evitar que as mudanças nas políticas econômica e comercial de um dos membros causem impactos negativos nos demais membros.

Alguns desdobramentos desta pesquisa são possíveis e seriam muito interessantes para melhor compreensão desse esquema de integração, como, por exemplo, a inclusão das importações, verificando o comércio total; outras formas do modelo gravitacional também são relevantes, como o modelo de efeitos fixos EF. No modelo EF há fatores específicos a cada par de comércio, tendo a equação gravitacional um intercepto para cada par de comércio Estado-país e um único intercepto para todos os fluxos de comércio bilaterais. Como aqui se analisaram quatro (4) países com relação a 43 países na amostra, então se obteriam 172 interceptos para os diferentes pares de comércio. Seria necessário aprofundar a análise desses interceptos para poder avaliar, com mais detalhes, os impactos do MERCOSUL sobre os fluxos de comércio de cada país-membro. ${ }^{12}$

\section{REFERÊNCIAS}

AITKEN, N. D. The effect of the EEC and EFTA on European trade: a temporal cross-section analysis. American Economic Review, v. 63, n. 5, p. 881-892, 1973.

ANDERSON, J. E. A theoretical foundation for the gravity equation. American Economic Review, v. 69, n. 1, p. 106-116, 1979.

ANDERSON, J. E.; VAN WINCOOP, E. Gravity with gravitas: a solution to the border puzzle. American Economic Review, v. 93, n. 1, 2003.

\footnotetext{
${ }^{12}$ Pode-se utilizar um modelo de efeitos fixos, como em Sá Porto e Canuto (2004).
} 
ASSOCIAÇÃO LATINO-AMERICANA DE INTEGRAÇÃO - ALADI. 2010. Disponível em: <www.aladi.org>. Acesso em: 14 de janeiro de 2010.

AZEVEDO, A. F. Z. de. O efeito do MERCOSUL sobre o comércio: uma análise com o modelo gravitacional. Pesquisa e planejamento econômico-PPE, v.34, n.2, p. 307-339, ago. 2004.

BALASSA, B. Trade creation and trade diversion in manufactures in the European Common Market. The Economic Journal, v. 71, p. 01-21, 1967.

BARBOSA, R. A. O Brasil e a integração regional: a ALALC e a ALADI (19601990). São Paulo: Universidade de São Paulo, Política Internacional e Comparada, II Seminário Nacional de Política Externa, 1991.

BERGSTRAND, J. $H$. The gravity equation in international trade: some microeconomic foundations and empirical evidence. The Review of Economics and Statistics, v. 67, p. 474-481, 1985.

. The generalized gravity equation, monopolistic competition, and the factor-proportions theory in international trade. The Review of Economics and Statistics, v. 71, p. 143-153, 1989.

BRÖCKER, J. Interregional trade and economic integration: a partial equilibrium analysis. Regional Science and Urban Economics, n. 18, p. 261-281, 1988.

CARDOSO, R. D.; BRAUN, M. B. S.; VIAN, E. F.; Uma análise do desenvolvimento do setor externo nos países do Mercosul através de indicadores de comércio internacional. In: CONGRESSO BRASILEIRO DE ECONOMIA, ADMINISTRAÇÃO E SOCIOLOGIA RURAL, 47., Porto Alegre (RS), 2019. Anais... Porto Alegre: SOBER/UFMS-UCDB, 2009. (CD ROM).

CEPAL. 2011. Disponível em: <http://www.eclac.org/>. Acesso em: 23 de maio de 2011.

CHENG, I.; WALL, $\mathrm{H}$. Controlling for heterogeneity in gravity models of trade. The Federal Reserve Bank of Saint Louis Working Paper, n. 99-010A, Saint Louis, 1999.

CUAIRAN, R.; SANSO, M.; SANZ, F. Bilateral trade flows, the gravity equation and functional form. Review of Economic and Statistics, v. 75, p. 266-275, 1993.

DEARDORFF, A. V. Does gravity work in a neoclassical world? In: FRANKEL, J. The regionalization of the world economy. University of Chicago Press, 1998.

HARRIGAN, J. Especialization and the volume of trade: do the data obey the laws? National Bureau of Economic Research. NBER Working Paper, n. 8.675, 2001. Disponível em: <http://www.nber.org/papers/w8675>. Acesso em: 15 maio 2010. 
HELPMAN, E.; KRUGMAN, P. Market Structure and Foreign Trade. Increasing Returns, Imperfect Competition, and the International Economy, Cambridge, MA: MIT Press, 1985.

LAMPREIA, L. F. Que futuro para o Mercosul? Classe inaugural do Ministro das Relações Exteriores na Cátedra Mercosul do Instituto de Estudos Políticos de Paris. 1999. Disponível em: <www.mre.gov.br>. Acesso em: 12 ago. 2010.

LINNEMANN, H. An econometric study of international trade flows. Amsterdam: North Holland, 1966.

MCCALLUM, J. National borders matter: Canada-U.S. regional trade patterns. American Economic Review, v. 85, n. 3, p. 615-623, 1995.

MELO, A. C. Mercosul em movimento: supranacionalidade e intergovernamentalidade no Mercosul. Porto Alegre: Livraria do advogado, 1999. MINISTÉRIO DO DESENVOLVIMENTO, INDÚSTRIA E COMÉRCIO EXTERIOR MDIC. 2008. Disponível em: < www.mdic.gov.br>. Acesso em: 11 maio 2010.

PÖYHÖNEN, P. A tentative model for the volume of trade between countries. Welwirtschaftliches Archiv, v. 90, n. 1, p. 93-99, 1963.

SÁ PORTO, P. C. de. Os impactos dos fluxos de comércio do Mercosul sobre as regiões brasileiras. 2002. 89 f. Tese (Doutorado em Ciências Econômicas) Universidade Estadual de Campinas - IE/UNICAMP, Campinas. 2002.

SÁ PORTO, P. C. de.; CANUTO, O. Mercosul: gains from regional integration and exchange rate regimes. Economia Aplicada, v. 6, n. 4, out./dez. 2002.

. Uma avaliação dos impactos regionais do MERCOSUL usando dados em painel. Pesquisa e Planejamento Econômico, v.34, n.3, dez. 2004.

SISTEMA DE ANÁLISE DAS INFORMAÇÕES DE COMÉRCIO EXTERIOR ALICEWEB. Site mantido pela Secretaria de Comércio Exterior - SECEX, e pelo Ministério do Desenvolvimento, Indústria e Comércio Exterior - MDIC. Disponível em: <http://aliceweb. desenvolvimento.gov.br/>. Acesso em: 23 jan. 2010.

TINBERGEN, J. Shaping the world economy: suggestions for an international economic policy. New York: Twentieth Century Fund, 1962.

UNITED NATIONS COMMODITY TRADE STATISTICS DATABASE - UN COMTRADE. 2010. Disponível em:

< http://comtrade.un.org/db/dqBasicQuery.aspx>. Acesso em: 15 out. 2010.

VERSIANI, F. R. As Experiências Latino-Americanas de Integração e os Novos Acordos Brasil - Argentina - Uruguai. In.: BAUMANN, R.; JUAN C. L. (Orgs.) Integração em Debate. Brasília: Ed. Marco Zero/Ed. Universidade de Brasília, 1987. 
WHITE, H. A Heteroskedasticity-consistent Covariance Matrix Estimator and a Direct Test for Heteroskedasticity. Econometrica, 48, 817-38, 1980.

WORLD ATLAS. 2010. Disponível em: < http://www.worldatlas.com/>. Acesso em: 15 maio 2010.

WORLD BANK. 2010. Disponível em: <www.worldbank.org>. Acesso em: 15 jan. 2011.

Submetido em 02/09/2013

Aprovado em 26/12/2016

\section{Sobre os autores}

\section{Rubiane Daniele Cardoso}

Doutoranda em Economia na Universidade Católica de Brasília

E-mail: rubicardoso@yahoo.com.br

\section{Mirian Beatriz Schneider}

Doutorado em Processos de Integração Transnacional Unión Europe pela Universidade de León, Espanha. Professora da Universidade Estadual do Oeste do Paraná - UNIOESTE.

Endereço para correspondência: Rua da Faculdade, 645. 85903620 - Paraná - Brasil.

E-mail: mirian-braun@hotmail.com

\section{André Ricardo Bechlin}

Mestre em Desenvolvimento Regional e Agronegócio pela Universidade Estadual do Oeste do Paraná, Campus Toledo. Professor Assistente da Universidade Estadual do Paraná - UNESPAR.

Endereço para correspondência: Rua Áustria, 679, Jardim Europa. 85.935-000 - Assis Chateaubriand - Paraná - Brasil.

E-mail: andre.bechlin@unespar.edu.br 